\title{
Enforcement and Spectrum Sharing: Case Studies of Federal- Commercial Sharing
}

\author{
Mohammed Altamimi \\ msa33@pitt.edu \\ School of Information Sciences \\ University of Pittsburgh \\ Pittsburgh PA
}

\author{
Mark McHenry \\ mmchenry@sharedspectrum.com \\ Shared Spectrum Company \\ Vienna VA
}

\begin{abstract}
To promote economic growth and unleash the potential of wireless broadband, there is a need to introduce more spectrally efficient technologies and spectrum management regimes. That led to an environment where commercial wireless broadband need to share spectrum with the federal and non-federal operations. Implementing sharing regimes on a non-opportunistic basis means that sharing agreements must be implemented. To have meaning, those agreements must be enforceable.

With the significant exception of license-free wireless systems, commercial wireless services are based on exclusive use. With the policy change facilitating spectrum sharing, it becomes necessary to consider how sharing might take place in practice. Beyond the technical aspects of sharing, that must be resolved lie questions about how usage rights are appropriately determined and enforced. This paper is reasoning about enforcement in a particular spectrum bands $(1695-1710 \mathrm{MHz}$ and $3.5 \mathrm{GHz})$ that are currently being proposed for sharing between commercial services and incumbent spectrum users in the US. We examine three enforcement approaches, exclusion zones, protection zones and pure ex post and consider their implications in terms of cost elements, opportunity cost, and their adaptability.
\end{abstract}




\section{Contents}

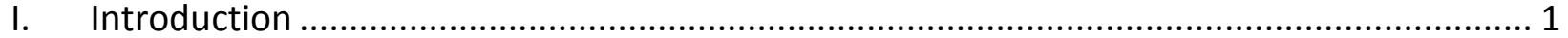

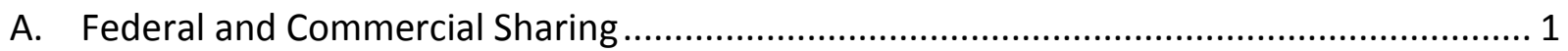

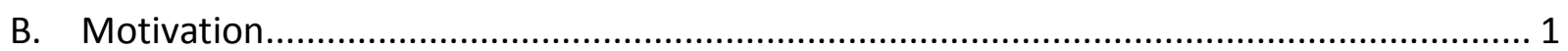

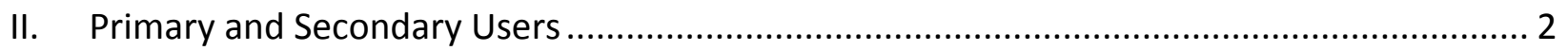

III. The General Aspects of Enforcement ........................................................................ 2

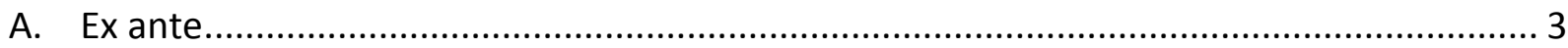

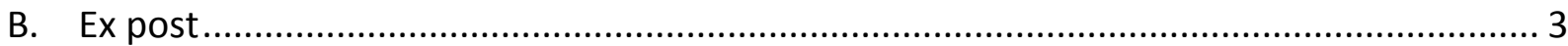

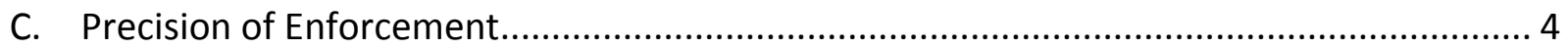

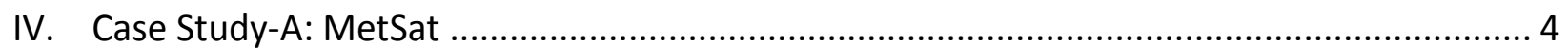

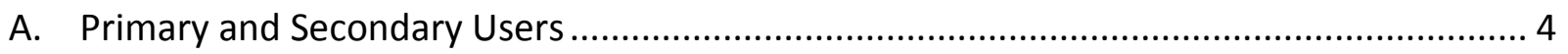

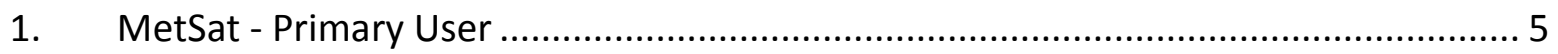

2. LTE - Secondary User ................................................................................ 5

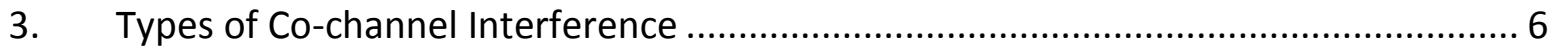

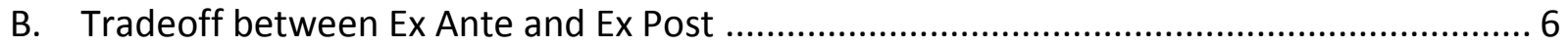

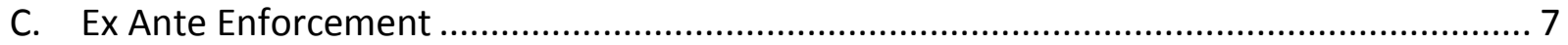

1. Exclusion Zones............................................................................................. 7

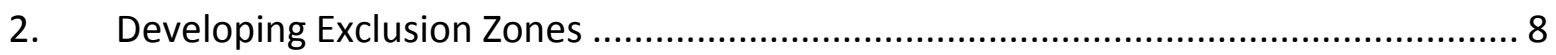

3. Opportunity Cost of Exclusion Zones ............................................................. 9

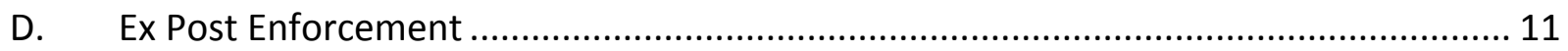

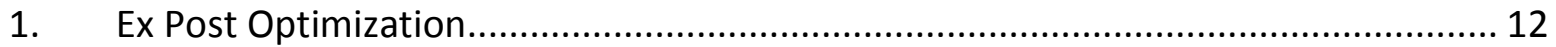

2. Cost Distribution of Ex Post Enforcement .................................................................. 12

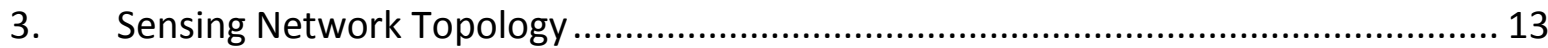

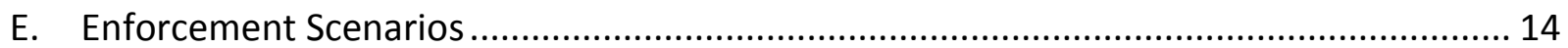

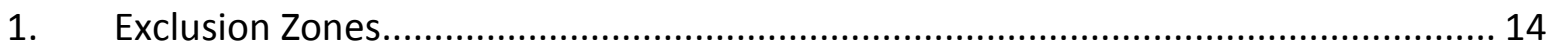

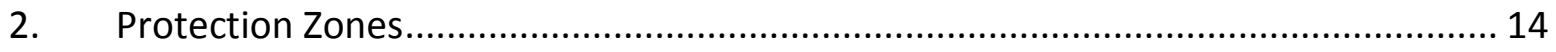

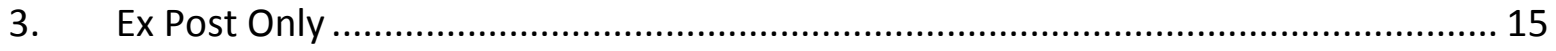

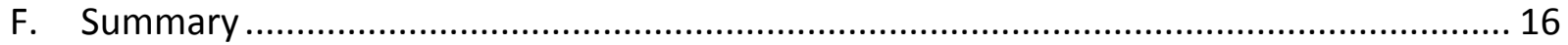

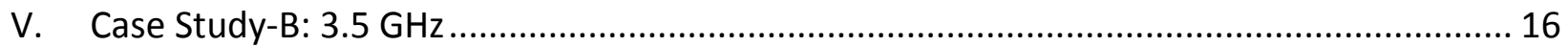

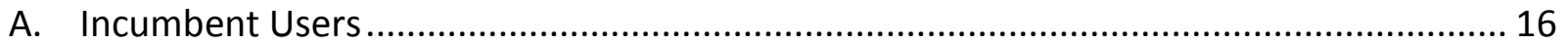

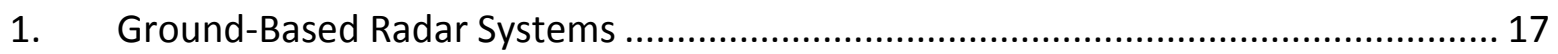

2. Airborne Radar Systems .......................................................................... 18

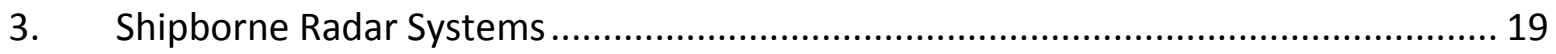


B. Why $3.5 \mathrm{GHz}$ ?

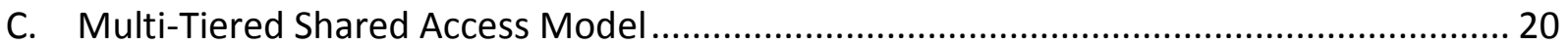

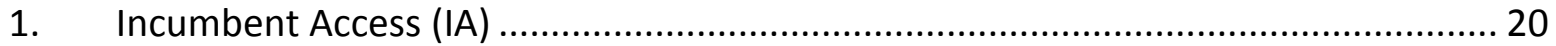

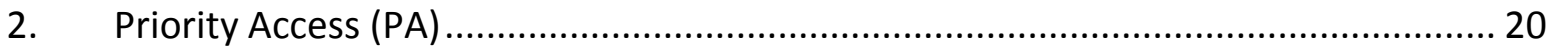

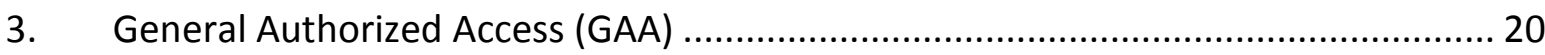

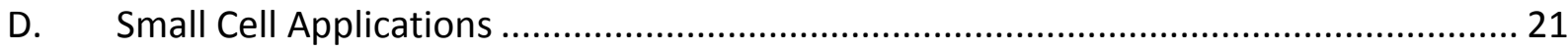

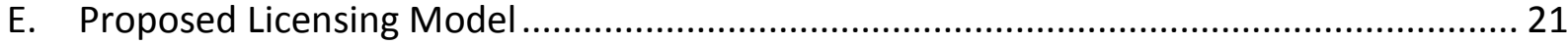

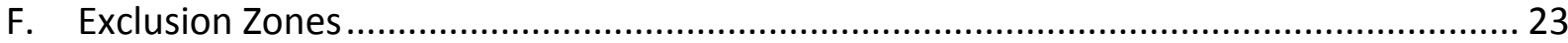

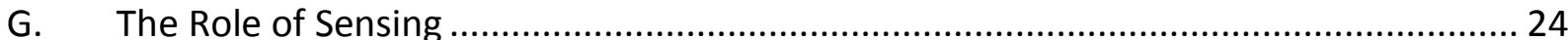

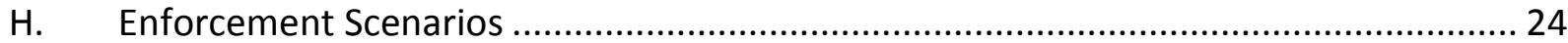

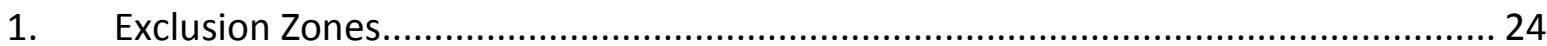

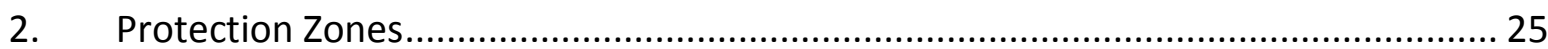

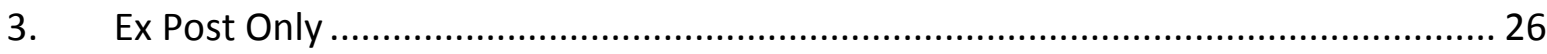

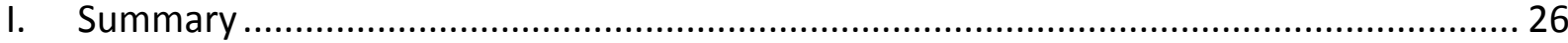

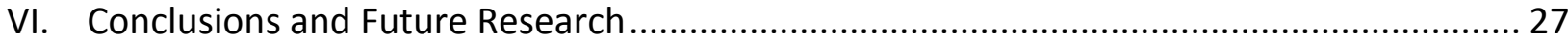

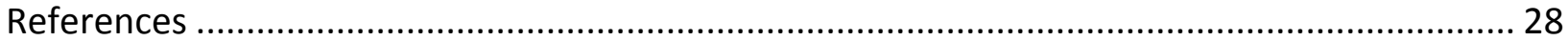




\section{Introduction}

The increasing demand for spectrum makes the introduction of more spectrally efficient technologies and management regimes essential. There is recent evidence that the demand for spectrum access rights exceeds the available supply [1] [2] [3]. One of the main factors leading to this imbalance is that the spectrum is not as well utilized as it could be. The future of wireless necessitates that we use spectrum resources more efficiently, which requires a transition to a future in which spectrum is shared more intensively. The growing demand pressure for expanded access for legacy and new uses and the need for significant spectrum reform to enable such sharing was noted by the Federal Communications Commission (FCC) Spectrum Policy Task Force, was reaffirmed by the National Broadband Plan [4] and the President's call for an additional $500 \mathrm{MHz}$ of spectrum for mobile broadband [5], and most recently in the PCAST report [6] on government spectrum. In addition, the National Telecommunications and Information Administration (NTIA) proposed several bands to facilitate spectrum sharing.

Realizing the future, where spectrum sharing is the norm requires us to commercialize next generation radio technologies such as Cognitive Radios (CRs) to enable the Dynamic Spectrum Access (DSA) systems needed to support higher spectrum utilization. These technologies enable new business models and spectrum sharing regimes that pose a host of opportunities and challenges for spectrum managers and the entire wireless ecosystem. DSA technology promises to increase spectrum access and help overcome the lack of available spectrum for new wireless services. DSA does this by enabling spectrum sharing between Primary Users (PU) and Secondary Users (SU).

\section{A. Federal and Commercial Sharing}

Spectrum sharing can take many forms of coordination between the PUs and SUs or even between the SUs themselves. The focus at this paper will be on non-opportunistic (or cooperative) sharing, where an agreement exists between the PUs and the SUs. Such an agreement is meaningless if it is not enforceable. Along with several researchers, the PCAST report points out that an important part of explicit spectrum sharing arrangements is the ability to enforce agreements.

Sharing between the government incumbents (i.e. Federal or non-Federal agencies) and commercial wireless broadband operators/users is one of the key forms of spectrum sharing that is recommended by the NTIA and the FCC. In addition, one of the broad visions of the President Obama's Spectrum Initiative [xx] is that the Federal government must ensure sound government performance and effective use of its spectrum, pushing for effective repurposing, sharing, and innovative uses of spectrum wherever possible. The NTIA issued reports [7] [8] to evaluate different Federal and non-Federal spectrum bands for the near-term viability of accommodating wireless broadband systems.

\section{B. Motivation}

As a consequence of the growth of wireless broadband demand and services of all types, there is an urgent need for on-going spectrum policy reform to make spectrum sharing a reality. In 
spectrum sharing, a spectrum entrant or secondary user is granted usage rights contingent upon the licensee's (or primary user's requirements or usage). With this policy change, it becomes necessary to consider how sharing might take place in practice. Generally speaking, spectrum can be shared in frequency, time and geographical dimension or any combination of those dimensions. Beyond the technical aspects of sharing, that must be resolved, lie questions about how usage rights are appropriately determined and enforced.

Weiss et.al. [9] examined the question of enforcement in a broad sense. The paper specifically addressed the relationship between ex ante and ex post enforcement measures, as well as taking the initial steps needed to relate the cost of enforcement to the needed precision. The authors urged the use of flexible arrangements since these agreements are still nascent. This paper advances this by reasoning about enforcement in particular spectrum bands $(1695-1710 \mathrm{MHz}$ and $3.5 \mathrm{GHz}$ bands) that are currently being proposed for sharing between commercial services (LTE) and an incumbent spectrum user in the US.

The analysis in this paper based on the recognition that some interference events are inevitable in spectrum sharing. Thus, the ex ante and ex post enforcement mechanisms serve to (1) separate the interference events by consequence on the primary user's operation and (2) reduce the probability of interference events that have a consequence that is considered significant.

\section{Primary and Secondary Users}

The NTIA issued reports [7] [8] to evaluate different Federal and non-Federal spectrum bands for the near-term viability of accommodating wireless broadband systems. Those bands include the 1675-1710 MHz, 1755-1780 MHz, 3500-3650 MHz, and 4200-4220 MHz, 4380-4400 MHz Bands. In this paper, the PUs are the Federal and non-Federal agencies whereas the proposed wireless broadband systems are the SUs.

Based on the scope of this paper and the proposed sharing between the Federal and commercial parties, the PU's applications can be fixed, portable or mobile. On the other hand, the SU could be centralized (single interface managing all the secondaries; e.g. LTE operator) or decentralized applications (ad hoc networks). Intuitively, if the PU uses the band for fixed services and the SU is centralized, spectrum sharing and the associated enforcement mechanisms will be simpler compared to other cases.

Two bands have been examined during this paper: $1675-1710 \mathrm{MHz}$ and $3500-3650 \mathrm{MHz}$ bands. In the $1675-1710 \mathrm{MHz}$ band, the PU is fixed and the expected SU is centralized (LTE mobile operator). For $3.5 \mathrm{GHz}$ band, the PU is mobile and the expected SUs are mixed with limited power transmission (small cells).

\section{The General Aspects of Enforcement}

The spectrum access rights granted by the Federal government to spectrum users come with the expectation of protection from harmful interference. As a consequence of the growth of wireless demand and services of all types, technical progress enabling smart agile radio networks, and ongoing spectrum management reform, there is both a need and opportunity to use and share 
spectrum more intensively and dynamically. A key element of any framework for managing harmful interference is the mechanism for enforcement of those rights.

As described in [9], there are two loci at which usage rights may be enforced: (1) ex ante: before a potentially harmful interference event has occurred; and (2) Ex post: after a potentially harmful interference event has occurred. Further, ex ante and ex post approaches work in tandem, not in isolation. Thus, a choice of an ex ante approach affects the ex post strategies.

The choice of how to design the enforcement mechanism directly and indirectly impacts the design and costs of usage rights enforcement. In particular, the costs of inducing good behavior (avoiding bad behavior) must be balanced against the social costs and benefits under different scenarios. So, the cost of strong ex ante rules is that they need to be enforceable and may pose the risk of overly restricting behaviors that may be welfare enhancing (e.g., innovation) as well as decreasing the value of the sharing opportunity for the entrant (i.e., SUs).

\section{A. Ex ante}

As described above, ex ante enforcement measures are designed to prevent co-channel interference from occurring. The development of exclusion zones - spatial regions where the SU may not operate - is a principal ex ante approach. The cost of an exclusion zone is felt in the value that the band has to (potential) secondary users. Most wireless operators value spectrum opportunities by $\mathrm{MHz}-\mathrm{POP}$ (that is, the population that each $\mathrm{MHz}$ of spectrum reaches) ${ }^{1}$. Thus, an exclusion zone in an area of significant population will have the consequence of decreasing its value. Minimizing the use of exclusion zones thus makes the sharing opportunity more attractive, especially in populous areas.

Generally speaking, spectrum can be shared in frequency, time and spatial dimension or any combination of those dimensions. So, if two parties are not sharing the spectrum on at least one of these three dimensions it is called an exclusive right for that electrospace. In this paper, sharing exists in two dimensions: spectrum and time with different levels in the spatial dimension. Exclusion zones are a special tool to facilitate ex ante enforcement mechanism, which prevents the harmful interference. Exclusion zones are not the only ex ante enforcement mechanism; However, it is the key one and less complicated.

\section{B. Ex post}

Weak ex ante enforcement mechanisms must often be paired with stronger ex post enforcement mechanisms to deal with the inevitable interference events. In above section, we addressed ex ante enforcement through the use of exclusion zones. Since ex post mechanisms involve the adjudication of actual interference events, they typically involve collecting information that can be used in agreed-upon adjudication procedures. In the absence of particular procedures (which would normally be negotiated between primary and secondary users), we can assume this

\footnotetext{
${ }^{1}$ Spectrum prices can vary significantly [22]. More recently, Verizon's AWS spectrum bid has been valued at $\$ 0.69$ per MHz-POP and Clearwire's spectrum has been valued at \$0.17-0.22 per MHz-POP

http://www.forbes.com/sites/elizabethwoyke/2011/12/02/telecom-deals-ratchet-up-price-of-wireless-spectrum/ (Last visit at 20 July 2013).
} 
information would include the detection of interference events attributable to the $\mathrm{SU}(\mathrm{s})$. It is likely that this information would include a time stamp and other information (such as the location at which the signal is detected) as well.

\section{Precision of Enforcement}

In general, we consider an enforcement approach to be more precise if it more specifically differentiates legitimate users and uses from illegitimate ones. The cost (including the complexity) of this depends on some attributes of the system itself. The maximum practical cost of enforcement is closely linked to the value of the resource: as the resource becomes more valuable, the more worthwhile it may be to invest in more precise enforcement technology.

For SUs, the most precise enforcement mechanism would be able to control/identify particular mobile device (part of SU's network) on a moment-by-moment basis based on factors such as the device's location and the primary user's instanteous usage. Ex ante enforcement would involve permission to transmit on the shared band and ex post enforcement would entail identifying the precise time and location of SU' devices whose signals exceeded the agreed-upon co-channel interference threshold. By contrast, the least precise enforcement mechanism would involve the creation of large exclusion zones as the ex ante mechanism, and a simple co-channel interference threshold detection system, perhaps with signal classifiers (to exclude nonsecondaries interference) but without any attempt at locating the interfering mobile.

\section{Case Study-A: MetSat}

The $1675-1710 \mathrm{MHz}$ frequency range $(35 \mathrm{MHz})$ is allocated to Meteorological-Satellite (MetSat; space-to-earth) and meteorological aids (MetAids; radiosondes) services. It is one the bands proposed by NTIA to accommodate new spectrum sharing between Federal/non-Federal and commercial usages. However, due to large number of fixed/transportable/mobile non-Federal meteorological-satellite earth station receivers that are unlicensed, and rely on meteorological data from weather satellites for public safety and other weather related activities, NTIA limited the expected sharing band to be the $1695-1710 \mathrm{MHz}$ band $(15 \mathrm{MHz})$.

Commerce Spectrum Management Advisory Committee (CSMAC) formed five working group to repurpose candidate bands for wireless broadband; one of them specifically focus on 1695-1710 $\mathrm{MHz}$ Weather Satellite Receive Earth Stations (WG1). According to the last update released from WG1 [10], sharing in the $1695-1710 \mathrm{MHz}$ band should be limited to commercial systems operations (LTE mobile uplink use only); because, in part, the $1695-1710 \mathrm{MHz}$ is immediately adjacent to the AWS-1 uplink band (which will maximize its usefulness for commercial services) and also because mobile uplinks transmit at much lower power than downlinks.

\section{A. Primary and Secondary Users}

Although, there is not much written about the technical specifications of MetSat-earth-stations (PU) or LTE-User-Equipment (LTE-UE) that could share the spectrum band, this section will provide brief information about the $\mathrm{PU}$ and $\mathrm{SU}$ in this band. 


\section{MetSat - Primary User}

The PU is the NOAA providing the weather satellite receive earth stations (MetSat) [8] [7]. NOAA operates both geostationary and polar-orbiting satellite transmitting systems in the 1675-1710 $\mathrm{MHz}$ band. NOAA, the Department of Defense (DOD), the National Aeronautics and Space Administration (NASA), the Department of Interior (DOI) and other Federal and non-Federal entities operate earth stations used to receive environmental research and weather data transmitted from the Geostationary Operational Environmental Satellite (GOES) Polar- Orbiting Environmental Satellites (POES). The Meteorological Aids (MetAids) are not considered in this paper $^{2}$. The GOES is for rapid real time observations of hurricanes, severe weather, short-range warning and weather forecast models. The POES is for high resolution real time hazard observations and weather forecast models.

MetSat is fixed service working in 1675-1710MHZ band (Space-to-Earth). The NTIA report [8] concluded that sharing was possible in the $1695-1710 \mathrm{MHz}$ band (15 MHz) between MetSat receive stations and wireless broadband systems. Originally, eighteen federal MetSat earthstations will continue to operate where they will be protected by exclusion zones. Based on the latest WG1 report [10], there are an additional 9 stations that need protection, resulting in a total of 27 earth stations. The interference from geostationary orbit and polar orbit meteorological satellite transmitters and radiosonde transmitters to "SU's base station receivers" was found not to be a problem (for more details, see Appendix-A).

\section{LTE - Secondary User}

The $S U^{3}$ is expected to be a commercial mobile LTE operator where the shared band would be used for uplinks from the handsets to the base stations and would be paired with the 2180-2200 $\mathrm{MHz}$ band for the downlink. From the SU perspective, there are many possible scenarios that may take place in this sharing environment. It is likely that single or multiple $\mathrm{SU}(\mathrm{s})^{4}$ sharing the band with MetSat at the same location. The SU has two possibilities; either it has exclusive LTE spectrum bands in addition to MetSat/LTE shared band $(1695-1710 \mathrm{MHz})$ or it will have only the shared spectrum band, see Figure (1). In case A, the LTE-UE will still have the connectivity by handing off from the shared band to an exclusive band. In case $B$, the LTE-UE will have no choice but to stop the service within the boundary of exclusion zones. It is most likely that this band will be shared by a LTE operator who has other exclusive LTE bands (case A).

\footnotetext{
${ }^{2}$ Based on NTIA analysis results, LTE-UE operated above $1695 \mathrm{MHz}$ will not cause interference to radiosonde receivers.

${ }^{3}$ In MetSat case, both "the LTE operator" and "its consumers' devices (LTE handsets)" are considered as a SU.

${ }^{4}$ Multiple SUs means multiple LTE operators and each one has his own users.
} 


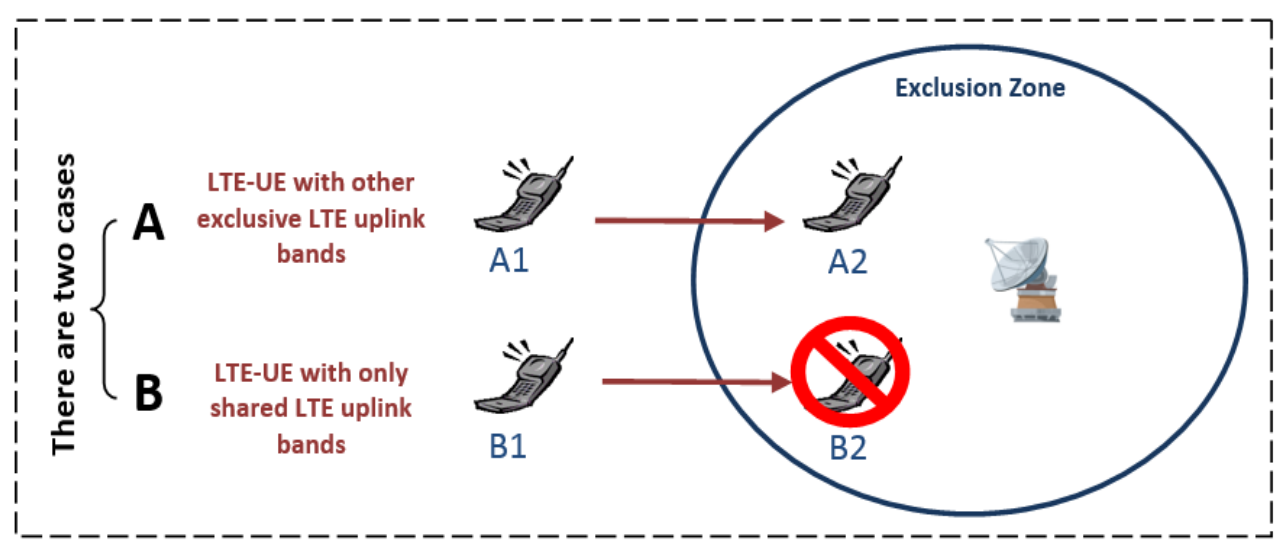

Figure (1): Shared and Exclusion LTE bands

\section{Types of Co-channel Interference}

Generally speaking, there are two types of co-channel interference that may exist due to the sharing scenario illustrated in this paper:

\section{i. Interference from $S U$ to $P U$ :}

This is the critical interference in this case where the PU should be protected. It is the interference from LTE-UE (i.e. user's handset) to MetSat-earth-station.

\section{ii. Interference from $P U$ to $S U$}

This type of interference is caused by MetSat satellite (space-to-earth) or "radiosonde transmitter" to SU base station (LTE-base-station). The exclusion zone size will defined based on MetSat-earth-station and LTE-UE characteristics only, not the satellite beam footprint. As a result of that, the space-to-earth signal will interfere with the LTE-basestations, which may need special filters to avoid this interference. The value of this shared spectrum (1695-1710) will be affected if the footprint of space-to-earth signal is very large compared to the exclusion zone size. This issue is not considered in this paper, where we assume that the SUs expected this before it shared the band.

\section{B. Tradeoff between Ex Ante and Ex Post}

In the case of MetSat and LTE sharing, the question (more precisely) is what the cost of various ex post enforcement mechanisms are and how that affects the ex ante rules, which, in turn, potentially affects the value of the secondary sharing. Currently, NTIA proposed mechanism has emphasized ex ante controls (e.g., a large exclusion zone) with no significant consideration of ex post mechanisms, i.e., the detection of events above certain level ${ }^{6}$ of Interference-to-Noise-Ratio that are clearly attributable to LTE and the adjudication of those events.

Shrinking the exclusion zone, the need for ex post action increases because we would expect the occurrence of potentially actionable events to increase. Figure (2) illustrates this idea.

\footnotetext{
${ }^{5}$ Here, the co-channel interference that already exists before sharing is not mentioned.

${ }^{6}$ At the NTIA Fast Track report analysis [8]; the value of SNIR was chosen to be (-10dB) which based originally on ITU-R Recommendation SA1026.
} 


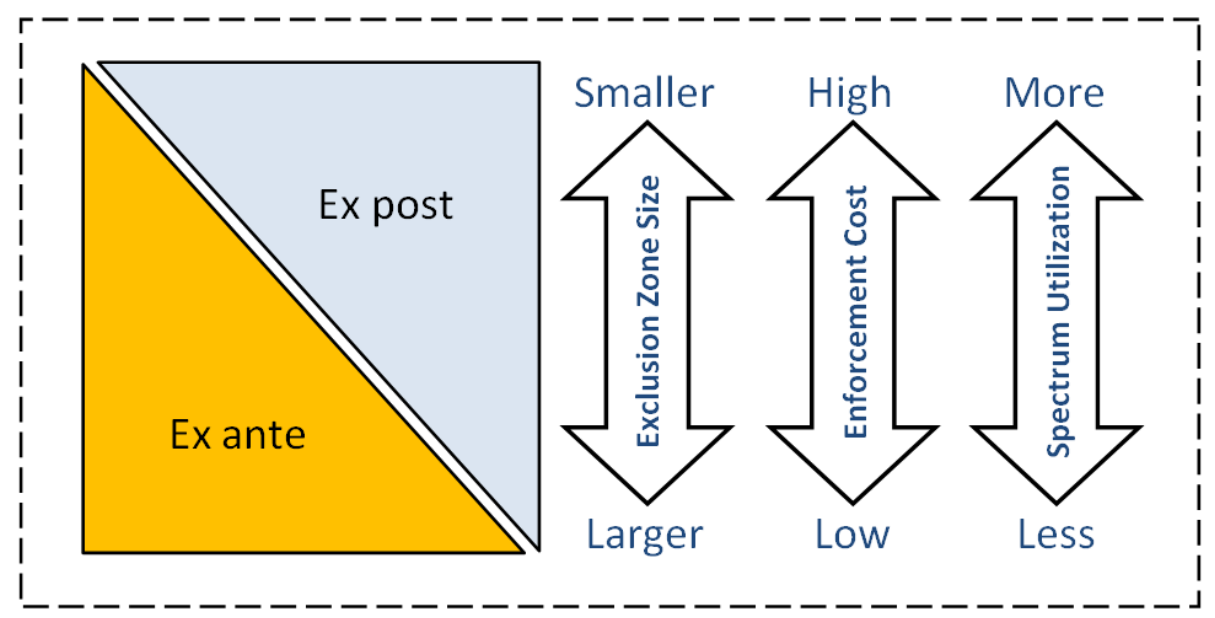

Figure (2): Tradeoff between ex ante and ex post enforcement.

\section{Ex Ante Enforcement}

As discussed above, the use of exclusion zones is the main tool to facilitate ex ante enforcement; however, it is not the only ex ante enforcement mechanism. If the focus is on minimizing significant interference events, an alternative ex ante approach could be for NOAA (in this case) to receive satellite transmissions from multiple geographically distributed earth stations (if the satellite footprint is large enough), some located in unpopulated areas. This diversity of reception from such statistically uncorrelated channels would allow significant interference events to be reduced. If this strategy is used in conjunction with exclusion zones, then it could reduce the size of exclusion zones, albeit at the cost of system re-engineering and post-reception data processing.

\section{Exclusion Zones}

Since the PU (MetSat) is a satellite-based system, much is known about their spectrum usage requirements. The frequency bands/channels are fixed, the orbits of the satellites are predictable and the technical specifications are known. As a result, constructing a database that summarizes all of this information that can be accessed easily by SUs is a straight-forward exercise. Since the SU is an LTE mobile operator, they have full management control over the remotes and provide for a single point for database access. Because of this, there is no need for the SU to sense the PU signal. Thus, the best cost effective context awareness technique [11] is the database approach. This conclusion is consistent with the PCAST report recommendation of using the database approach in this type of spectrum sharing environment [6].

The radius for each exclusion zone was computed based on aggregate interference from wireless broadband systems. The exclusion zone analysis took into account: (1) representative technical and deployment characteristics for the LTE handsets; and (2) representative technical characteristics of MetSat-earth-stations. 


\section{Developing Exclusion Zones}

Some MetSat-earth-station parameters and technical specifications are well known and fixed, such as geographical location and antenna gain. While this information is needed to measure the allowable interference threshold, it can be supplemented with dynamic information, which will require the $\mathrm{SU}$ to be connected continuously and which allows for small exclusion zones. There are three level of dynamicity; detailed as follow:

\section{i. Dynamics of Exclusion Zones}

Since the antenna orientation of the MetSat-earth-station is not fixed, the use of fixed exclusion zones represents a worst-case solution. In any particular reception episode, the exclusion zone is ovate, as shown in Figure (3). If a static exclusion zone is used, it must be the union of all possible antenna positions. It would thus be large compared with the exclusion zone associated with a particular receiving episode. From the NTIA report [8], Appendix-B shows the exclusion zone radius around the MetSat-earth-stations ${ }^{7}$.

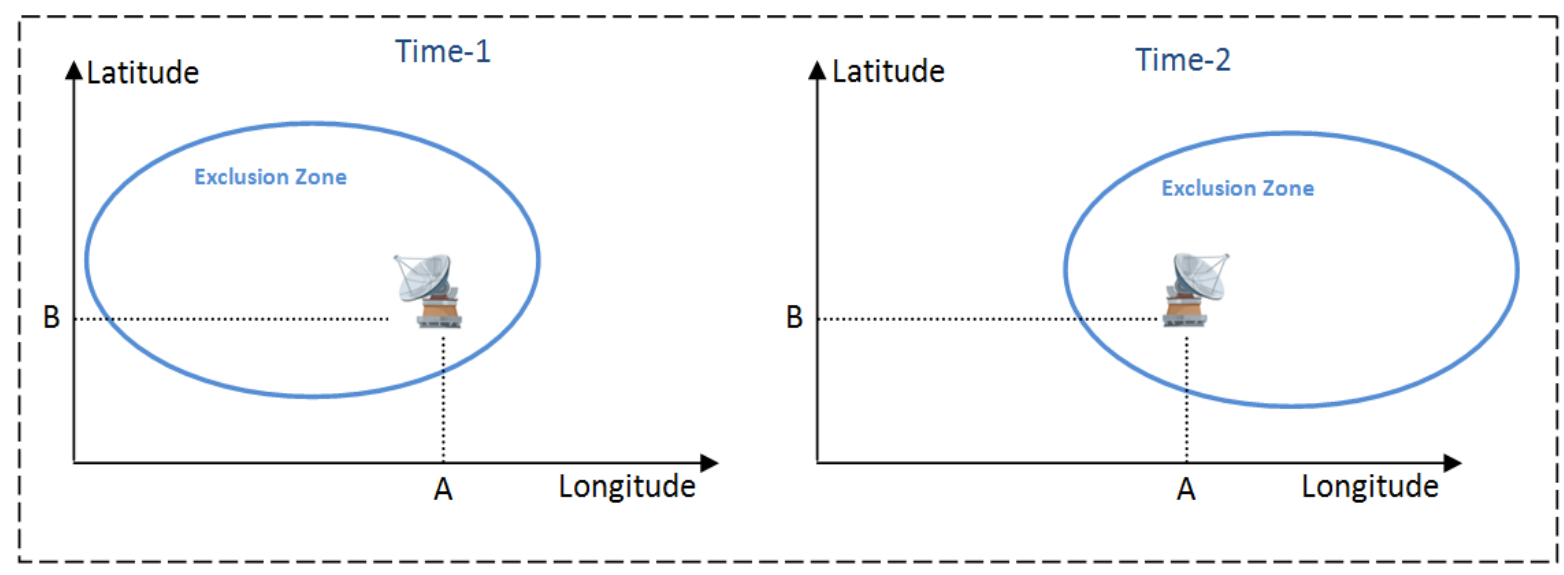

Figure (3): It illustrates the concept of Dynamic Exclusion Zones; the exclusion zone will shift and vary based on the orbit parameters and technical specifications (the base-station is fixed).

If exclusion zones could be focused on the current signal reception episode, then the particulars of the satellite orbit could be considered and the exclusion zone could be reduced in size to account for the earth station's instantaneous antenna position. SUs would use the database to adjust their transmission footprint in real time to avoid the exclusion zone. As a result, the size of the exclusion zone would be smaller at any point in time than a static exclusion zone. However, the SU's spectrum opportunity would be interruptible near the earth station, resulting in spectrum sharing similar to what might be found with rotating beam radars [12].

\footnotetext{
${ }^{7}$ The exclusion zone were considered large enough to protect the MetSat-earth-stations regardless of station movement (fixed exclusion zone).
} 


\section{ii. Satellite Channel}

Basically, the MetSat system works in the band $1675-1710 \mathrm{MHz}$ as illustrated below. So, at single point of time, the MetSat-earth-station will receive the signal via one channel in this band (assuming the antenna can receive one channel at a time). The shared portion of this band is just $15 \mathrm{MHz}$ (less than $50 \%[15 \mathrm{Mhz} / 35 \mathrm{MHz}]$ ); see Figure (4).

As an example, if we take the technical specification of the Monterey, California earth station (see Table (1)), we find that there are three center frequencies (i.e. channels) that are used to receive the satellite signal $(1698,1702.5 \text { and } 1707)^{8}$. For each channel, there will be a separate dynamic exclusion zone. If the station is receiving at any channel outside this $15 \mathrm{MHz}$ (i.e. within the $1675-1695 \mathrm{MHz}$ ), then there is no exclusion zone at that point of time.

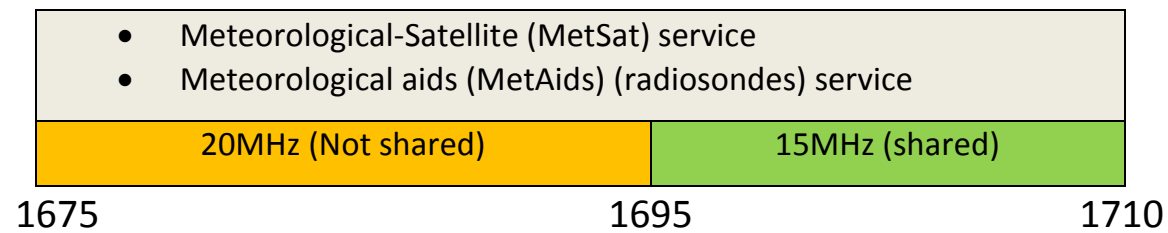

Figure (4): Tradeoff between ex ante and ex post enforcement.

\begin{tabular}{|l|l|}
\hline \multicolumn{1}{|c|}{ Parameter } & \multicolumn{1}{c|}{ Value } \\
\hline Center Frequency (MHz) & $1698,1702.5,1707$ \\
\hline Receiver 3 dB Intermediate Frequency Bandwidth (MHz) & 1.33 \\
\hline $\begin{array}{l}\text { Receiver IF Selectivity (relative attenuation (dB) as a function of } \\
\text { frequency offset (MHz)) }\end{array}$ & $-3 \mathrm{~dB} @+/-0.6655 \mathrm{MHz}$ \\
$-20 \mathrm{~dB} @+/-1.34 \mathrm{MHz}$ \\
$-60 \mathrm{~dB} @+/-12 \mathrm{MHz}$
\end{tabular}

Table (1): Receiver Equipment, Monterey, California, HRPT [8].

\section{Opportunity Cost of Exclusion Zones}

There are 27 MetSat fixed earth stations that need protection; see Figure (5) and exclusion zones have been proposed for each [7] (Details in Appendix B) ${ }^{9}$. Since there are large areas between those stations that are not part of an exclusion zone, significant spectrum sharing opportunities exist. However, some of the exclusion zones are in areas that have significant POPs (e.g., Washington DC or Miami FL), so reducing exclusion zones can have a significant impact on the value of the spectrum opportunity for SUs.

\footnotetext{
${ }^{8}$ Based on NTIA fast track repost, these three channels (centered at 1698, 1702.5 and $1707 \mathrm{MHz}$ ) are used by POES Meteorological-Satellites to send "High Resolution Picture Transmission" service.

${ }^{9}$ Note: originally, there are only 18 earth-stations addressed at NTIA report published at Oct. 2010 [8].
} 


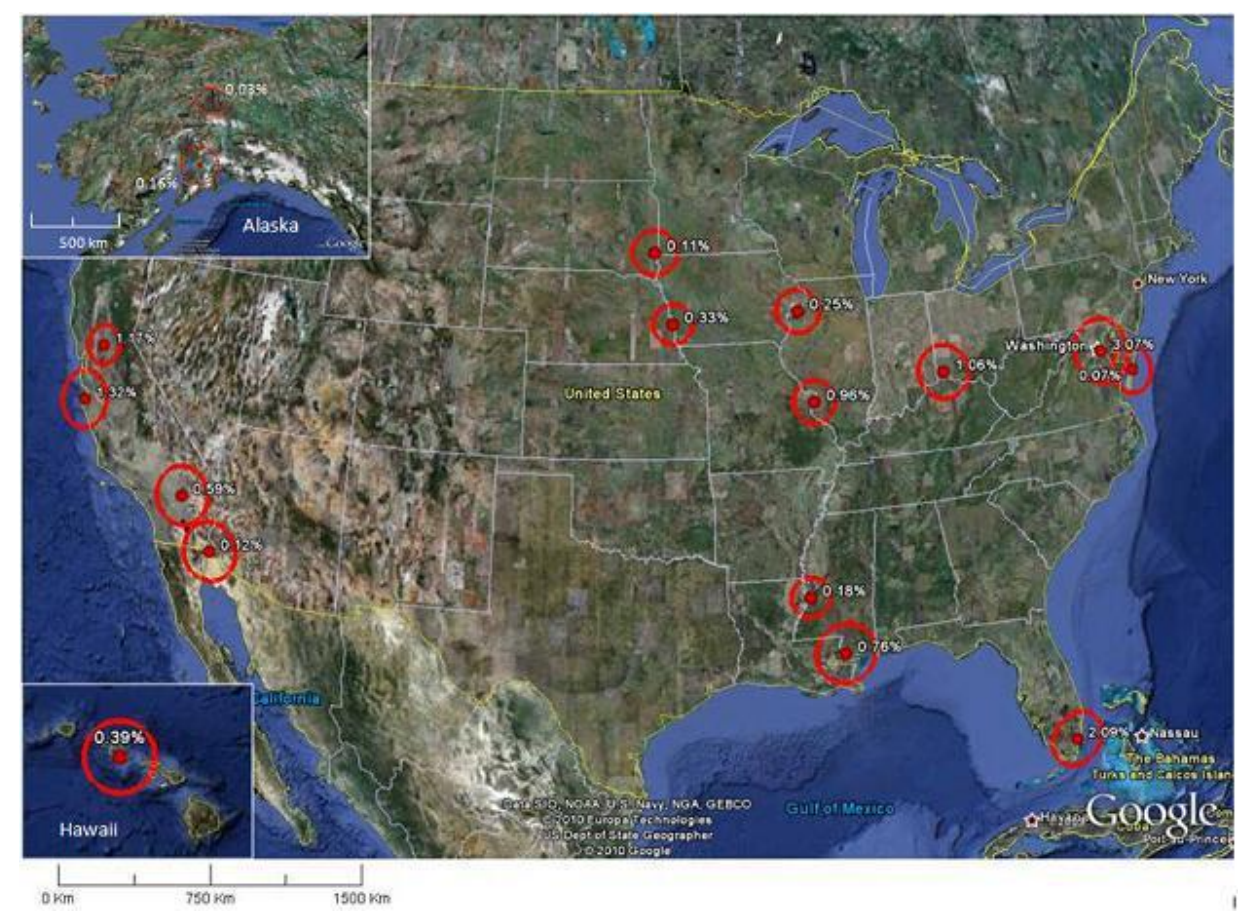

Figure (5): Federal MetSat receive stations.

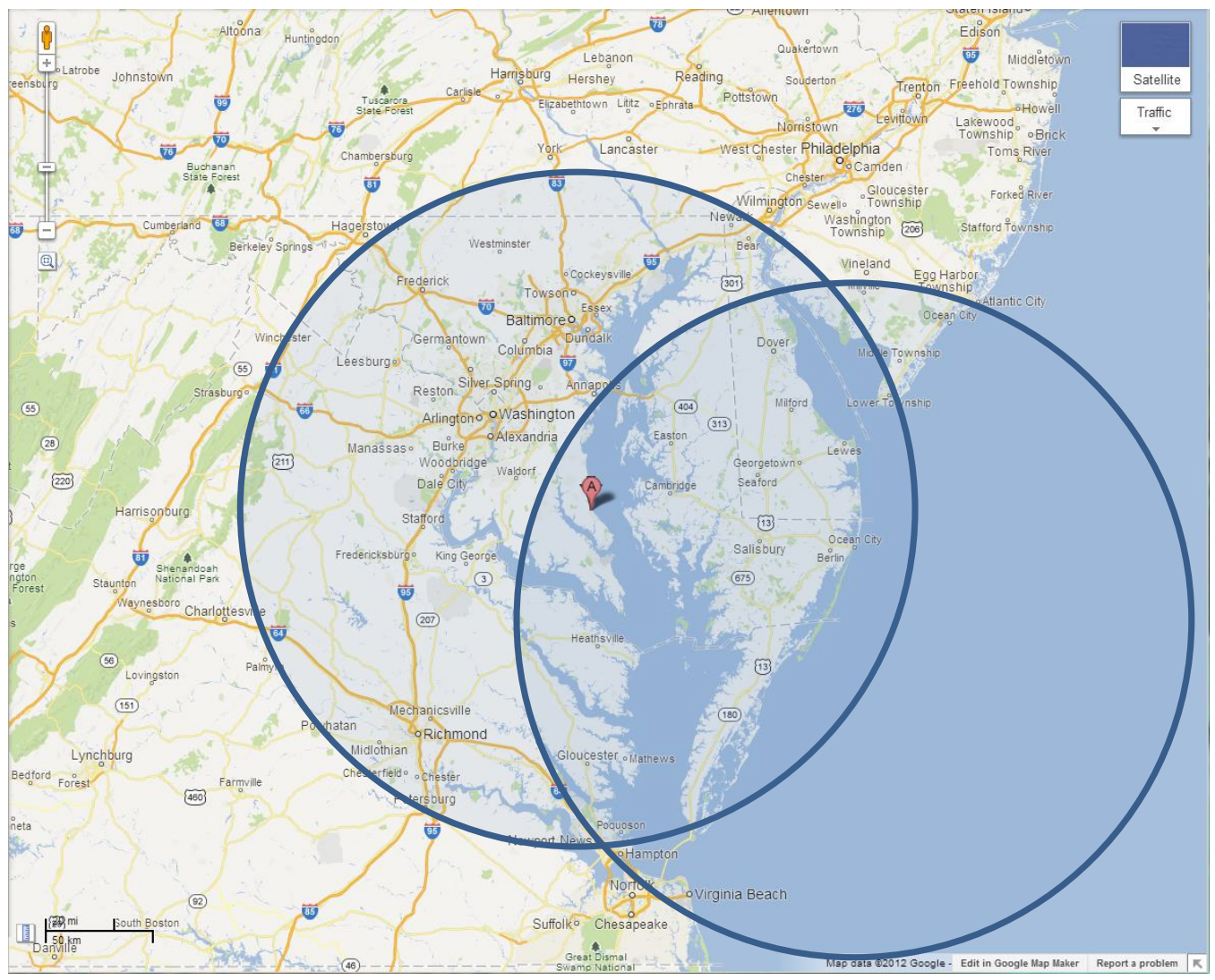

Figure (6): Approximate Exclusion zones for Suitland, MD and Wallops Island, VA 
Figure (6) illustrates the proposed static exclusion zones for the Washington, DC area (for the MetSat earth stations in Suitland, MD and Wallops Island, VA (based on NTIA calculations) [13]. These exclusion zones effectively cover the populations of the Richmond VA, the Washington DC Metro area, the Baltimore MD metro area and possibly the Norfolk, VA and the Wilmington DE metro areas. Excluding the rural populations, this amounts to roughly 11.5 million people. With a bandwidth of $15 \mathrm{MHz}$, this area would represent 172.5 million POPs for a wireless operator. Using Verizon's valuation of the nearby AWS band in their proposed spectrum swap, this exclusion zone is "worth" approximately \$119 million. Small reductions in the exclusion zone would have significant payoffs: reducing the zone so that Richmond VA would no longer be excluded would be worth approximately $\$ 13.5$ millon; shrinking the exclusion zone so that it avoids Baltimore would be worth almost $\$ 28$ million. Of course, the biggest prize in this is the Washington DC metro area; the $15 \mathrm{MHz}$ of spectrum in question would be worth approximately \$58 million.

These costs are directly borne by the SUs as their spectrum use is affected by the exclusion zone. However, if the SU is cooperative, then the costs of the exclusion zone would be shared by the $\mathrm{PU}$ in that contract prices would be lower.

In the case of MetSat, sharing is being "encouraged" by the NTIA, acting as spectrum manager for federal spectrum use. If SUs of the $1695-1710 \mathrm{MHz}$ band do not incur direct costs for this use, then agencies would have an incentive to develop large exclusion zones, as the cost would be borne entirely by the SUs. If SUs must pay for the right of secondary use, then the costs would be shared because SUs would rationally pay less if the exclusion zones were large. If the PU did not recognize clear benefits to sharing, exclusion zones would again be large because the PU would be bearing the cost of interference without an offsetting benefit.

\section{Ex Post Enforcement}

Exclusion zones do not provide a guarantee of co-channel interference avoidance. Since propagation is unpredictable, uplink signals could occasionally travel farther than expected. Furthermore, the exclusion zones do not explicitly account for tall features, like tall buildings and mountains that can cause longer than expected propagation distances. As a result, ex post mechanisms may be needed to provide data to PUs and SUs to further tune the system for future interference avoidance or to optimize the sharing system to better state.

Attributing an interference event to a SU is necessary for appropriate adjudication. It is not reasonable to hold SUs accountable for interference events that they did not cause. For example, inter-modulation products from a nearby but unrelated user could cause significant electromagnetic energy to occur in the PU's band, causing interference. To associate interference event with the SU(s) means that the PU has either some knowledge about the SU's signal characteristics and/or an identification code that can easily be obtained by demodulating part or all of the SU's signal. For example, in the case of MetSat, the uplink sharing is an LTE-UE, which has a distinct electromagnetic signature. Also in this case, the $15 \mathrm{MHz}$ of bandwidth that is being proposed for sharing implies that only one LTE secondary user would exist in any sharing zone. Thus, demodulation of the LTE signal to uniquely identify the SU may not be necessary, 
reducing ex post enforcement costs. If multiple SUs exist, the LTE signal would have to be demodulated to identify the source of the interference, which is more costly.

As was argued in [9], spectrum sharing is a complex dynamical multi-stakeholder systems that could benefit from the feedback provided by practice; so that the system can be optimized to perform "better" (by whatever set of attributes). A collaborative, adaptive approach to ex ante and ex post enforcement could result in benefits to both parties. The PU could look forward to a decreasing rate of significant interference events and the SU could look forward to reduce ex ante rules (exclusion zones) that would allow them to use the shared spectrum as effectively as possible.

\section{Ex Post Optimization}

Following the law and economics literature, the purpose of enforcement is to make rights definition meaningful. If we assume rational economic actors, we can establish some parameters around penalties as well as enforcement costs.

Penalties serve (1) to promote cooperation between primary and secondary user and (2) to compensate for violations. In the case of MetSat, the PU is interested in preserving their ability to receive a weak signal, so it is difficult to conceive of a scenario in which a SU is harmed. Thus, in the analysis below, we assume that a SU can harm the PU, but not vice versa.

To ensure cooperation, the SU should find it cheaper to cooperate than to pay the penalty. Thus, the product of the penalty and the probability of detection should be greater than the benefit the SU obtains from transmitting in a way that causes interference. In particular, $\mathrm{d} \times \mathrm{P} \geq \mathrm{B}$, where $d$ is the probability of detection and successful adjudication, $P$ is the penalty paid and $B$ is the benefit the SU obtains from transmitting in a way that causes interference. The uncertainties of RF propagation mean that interference events may be accidental. If the average payment is based on willful interference, the SU will (1) have an incentive to optimize their system to eliminate interference events and (2) be indifferent to intent (i.e., willful or accidental).

\section{Cost Distribution of Ex Post Enforcement}

Given the asymmetry of the MetSat case, ex post enforcement means that the PU must present evidence to an adjudicator in support of a claim of interference ${ }^{10}$. As well, they may need to provide evidence that the interference event was disruptive. Gathering evidence to support an interference claim would almost certainly require the existence of a sensor in the immediate proximity of the MetSat earth station in the direction of the main lobe of the antenna (during any receive episode). This sensor must be able to (1) detect signal energy at or above an agreedupon interference threshold and (2) determine if the signal energy could reasonably be attributed to the SU.

In the MetSat case, the $15 \mathrm{MHz}$ of bandwidth in question virtually guarantees that a single SU exists, and all case studies presented to date indicate that the SU would be an LTE operator. Thus,

\footnotetext{
${ }^{10}$ In the US, it is not at all obvious who the adjudicator should be. The FCC retains responsibility for commercial spectrum management and the NTIA for civilian federal spectrum management. Further, courts have jurisdiction for resolving property disputes. Thus, the adjudication venues must be defined in advance.
} 
the sensor must be able to distinguish an LTE signal in the passband from other electromagnetic energy above the threshold. In addition, for long term credibility, the detection mechanism must be free from incentives to over- or under-report events. While a variety of institutional arrangements may be possible, it is likely than an independent sensor network (similar to what was proposed in [14]) would emerge as an SU might distrust a PU-operated sensing system (and vice versa) because the PU would have an incentive to maximize penalty payments from the SU.

It is likely that the sensing would be performed (at least) by the PU, since they would be making claims for adjudication. SU may wish to have an independent sensor to (1) validate the claim of the PU and (2) provide additional information that the PU may not provided. Such additional information might include the direction of the interfering signal and the ID of the mobile unit that transmitted the offending signal. A mutually trusted third party could also provide sensing information [15] to both the primary and secondary users if the costs of sensing are too high.

\section{Sensing Network Topology}

As mentioned above, there is a need for a sensing network that should be able to detect interference events that caused by SUs as part of ex post enforcement. It is a critical part of the enforcement process (i.e. ex post side) in this shared environment. There is a tradeoff between the cost of sensing network and its accuracy to detect the interference events. Here is a list of possible topologies that will elaborate more about the cost and precision in this regards.

\begin{tabular}{|c|c|c|c|c|c|c|c|}
\hline Type & \multicolumn{2}{|c|}{ Enforcement } & $\begin{array}{l}\text { Exclusion } \\
\text { Zone Size }\end{array}$ & $\begin{array}{c}\text { Sensing } \\
\text { Cost }\end{array}$ & $\begin{array}{l}\text { Spectrum } \\
\text { efficiency }\end{array}$ & $\begin{array}{c}\text { Enforcement } \\
\text { precision }\end{array}$ & Comments \\
\hline \multirow{2}{*}{ A } & Ex ante & $100 \%$ & \multirow{2}{*}{ Largest } & \multirow{2}{*}{ Nothing } & \multirow{2}{*}{ Lowest } & \multirow{2}{*}{ N/A } & \multirow{2}{*}{$\begin{array}{l}\text { No sensing network. This is just } \\
\text { hypothetical topology that we do } \\
\text { not expect to be realistic. }\end{array}$} \\
\hline & Ex post & $0 \%$ & & & & & \\
\hline \multirow{2}{*}{ B } & Ex ante & $90 \%$ & \multirow{2}{*}{ Large } & \multirow{2}{*}{ Low } & \multirow{2}{*}{ Low } & \multirow{2}{*}{ Very low } & \multirow{2}{*}{$\begin{array}{l}\text { Single sensing tower at the } \\
\text { MetSat location. }\end{array}$} \\
\hline & Ex post & $10 \%$ & & & & & \\
\hline \multirow{2}{*}{$\mathbf{E}$} & Ex ante & $50 \%$ & \multirow{2}{*}{ Medium } & \multirow{2}{*}{$\begin{array}{l}\text { High/ } \\
\text { Medium }\end{array}$} & \multirow{2}{*}{ Medium } & \multirow{2}{*}{ Good } & \multirow{2}{*}{$\begin{array}{l}\text { Sensing Network around the } \\
\text { exclusion zone to detect any SUs } \\
\text { entering the exclusion zone. This } \\
\text { type is possible if there is high level } \\
\text { of trust between the PU and SUs. }\end{array}$} \\
\hline & Ex post & $50 \%$ & & & & & \\
\hline \multirow{2}{*}{ D } & Ex ante & $30 \%$ & \multirow{2}{*}{ Small } & \multirow{2}{*}{ High } & \multirow{2}{*}{ High } & \multirow{2}{*}{ Accurate } & \multirow{2}{*}{$\begin{array}{l}\text { Sensing Network around and } \\
\text { within the exclusion zone. It is the } \\
\text { most expected topology especially } \\
\text { at the early stage of sharing } \\
\text { process. }\end{array}$} \\
\hline & Ex post & $70 \%$ & & & & & \\
\hline
\end{tabular}

Table (2): Possible sensing network topologies. 


\section{E. Enforcement Scenarios}

\section{Exclusion Zones}

Static exclusion zones would rely largely on a database. This database would be an operational mechanism by which each exclusion zone would be defined. It is likely that the PU would maintain a reference database that would be copied by the SUs and incorporated into their operational LTE networks. While a static exclusion zone is relatively straight-forward to enforce, it has high opportunity costs, as noted above. Even with exclusion zones, co-channel interference is possible. If exclusion zones are sized to avoid interference, then there may not be a strong basis for ex post action, except to determine if the interfering station was located within the exclusion zone during the interference episode. Unless there is a sensor network that broadly covers the exclusion zone, then it will be difficult to offer concrete evidence of SU transmission within the exclusion zone.

Ex post enforcement in this scenario could be used to (1) tune the contours of the exclusion zones to optimize operations and/or (2) detect violations of the exclusion zone by SUs. The costs of the objectives are quite different. In (1), a sensor network to localize the strength and direction of SU associated interference events is sufficient. This would require sensing near the PU's earth stations. Eight sensors may be sufficient to provide the information needed to optimize the exclusion zone (through the database) to minimize interference events. In (2), the sensor network would have to be more comprehensive since the PU would seek to demonstrate SU operation within the exclusion zone. This cannot be done definitively from the PU earth station, so a network of sensors would have to be constructed. The costs become higher, as signal detection and localization capability for the entire exclusion zone must be provided. The number of sensors would clearly be higher in the case.

\section{Protection Zones}

Recently, CSMAC proposed to eliminate exclusion zones entirely in favor of protection zones [16]. This would allow SU operation as long as the aggregate received co-channel interference at the $\mathrm{PU}$ antenna is below a yet to be determined threshold ${ }^{11}$. Protection zones are smaller than exclusion zones (14-95 km vs $72-121 \mathrm{~km}$, depending on the location in question). For the Suitland MD site, the protection zone still encompasses the Washington DC metro area.

This scenario essentially reorganizes the locus of enforcement from ex ante toward ex post, since protected zones would definitely require spectrum sensing and an adjudication procedure. Because transmission could be permitted in the protection zone, its opportunity cost would likely be substantially lower than that of the exclusion zone (\$1.1 billion according to [17]).

In the case of protection zones, sensing at the PU's earth station is sufficient, as the metric of interest is the IPSD ${ }^{12}$. The sensors must be configured to measure this value and attribute it

\footnotetext{
${ }^{11}$ The CSMAC Working Group 1 Final Report [15] uses a new Interference Power Spectral Density (IPSD) measure as the essential threshold.

12 It should be noted that this sensing metric (i.e. IPSD) at the PU's location is different from the sensor network idea, they can work together to perform different jobs. Both are part of ex post enforcement.
} 
appropriately to the $\mathrm{SU}(\mathrm{s})$. This may require somewhat more post processing to estimate low level IPSD values, but may not result in significantly more costly sensors.

The existence of this zone also implies a database that defines its boundary. Thus, this approach would have to use a database similar to the exclusion zone approach. Operationally, the SUs would have to estimate the signal energy they are generating within the protection zone so as not to exceed the IPSD threshold. Feedback from sensors around the PU's earth station would be critical to optimizing this approach.

The larger unknown is the cost of ex post enforcement. The Final Report [10] does not address adjudication or the consequences of exceeding the IPSD threshold. If an adjudication procedure exists, then the interference events must be documented and attention paid to issues such as provenance and chain-of-custody, which requires back-end information system expenses. It may also require ongoing attention of an individual to act as a liaison between the adjudicator and/or the secondary user.

The protection zone is always dynamic and will change with time and LTE-UE density. Since the metric based on aggregated interference level at the PU location, it depends on the number of active LTE-UE around it. If there are only a few LTE-UE around, it would be relatively small, becoming larger as the number of LTE-UEs increase. Thus, the zone boundaries will move based on the activity of the SUs.

\section{Ex Post Only}

Taken further, the parties could rely exclusively on ex post enforcement. In such a scenario, the penalties for interference would be set so that the SU would have an incentive to discover profit maximizing protected zones. That is, if the cost of interference is sufficiently high, the SU would find it advantageous to modify their behavior in a way that balances the consequence of interference with the consequence of not transmitting in a region. Such a system would require regular calibration of the interference penalties so that the PU's operational SINR can be attained.

This approach would not require a database (i.e. database that defines the boundary of a zone) and therefore assumes that the SU would handle this mission at its expense. It would require the establishment and operation of a sensor network as well as the adjudication-oriented information system. If adjudication can be automated, this approach could perhaps be made more efficient; see figure (7) for an illustration of expected sizes of these different enforcement scenarios zones.

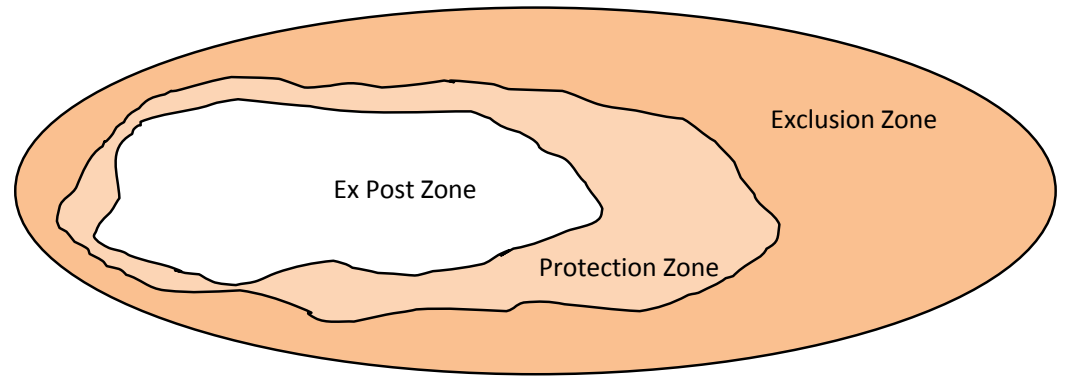

Figure (7): Example of different enforcement scenarios show the relative size of each one to the others. 


\section{F. Summary}

The approach that outlines obligations most clearly is the "exclusion zone" enforcement scenario. This scenario requires a database and an extensive sensor network and an as-yet poorly defined adjudication system. This approach also has the highest opportunity cost and provides the fewest opportunities for adaptive learning.

The "protection zones" enforcement scenario defines a maximum IPSD that can be present at the PU's earth station, and permits some operations in the (smaller) protection zones as long as the IPSD is not exceeded. This also requires the development of an ex post adjudication procedure. This enforcement scenario would also require a database, though it may be sufficient to have sensors near the earth station and not throughout the protection zone. The opportunity cost for this scenario would clearly be smaller than the exclusion zone scenario, since the protection zones are smaller and some operations within them are permitted. Without a detailed analysis, one could assume that the opportunity cost scales linearly with the ratio of the populations affected by the two types of zones. Since some operations are permitted inside the protection zone, this approach is more amenable to learning and adaption.

The final one is the "ex post only" enforcement scenario. Here, a database would not be needed, and a sensor network surrounding the earth station would be sufficient. A robust and efficient adjudication system with predictable outcomes and penalties would be important in this scenario, however, since it is likely that more interference events would occur. This would result in a highly flexible and adaptive system and one that could yield ex ante rules that are aimed at reducing adjudication costs in the future.

\section{Case Study-B: $3.5 \mathrm{GHz}$}

In the Fast Track report [8], NTIA recommended reallocating 100 megahertz of the 3550-3650 $\mathrm{MHz}$ band for wireless broadband use within five years (Fast Track report published in October 2010). In this section, we will describe the recommended sharing scenarios from enforcement point of view.

\section{A. Incumbent Users}

The $3500-3650 \mathrm{MHz}$ band ${ }^{13}(150 \mathrm{MHz})$ is used by DoD radar systems with installations on land, ships and aircrafts. Based on the NTIA [8], most of the aircraft and land-based systems are operated at military training areas and test ranges, recognizing that tactical necessities ultimately determine operational requirements. Functions performed by these systems include search for near-surface and high altitude airborne objects, sea surveillance, tracking of airborne objects, air traffic control, formation flight, and multi-purpose test range instrumentation [8].

After considering options to reallocate the entire $3500-3650 \mathrm{MHz}$ or to reallocate a portion of it, the NTIA concluded that the $3550-3650 \mathrm{MHz}(100 \mathrm{MHz})$ band offers an opportunity to implement wireless broadband over large portions of the United States.

\footnotetext{
${ }^{13}$ It should be noted that all the NTIA analysis based on the band $3500-3650 \mathrm{MHz}(150 \mathrm{MHz})$; in the end they recommend the use of the upper $100 \mathrm{MHz}(3550-3650 \mathrm{MHz})$.
} 
The types of analysis that were performed in assessing compatibility between wireless base stations and mobile/portable stations and Federal systems operating in the $3500-3650 \mathrm{MHz}$ band are summarized in appendix-C. The following subsections will cover the main type of PUs at this band. It should be noted that there are non-Federal uses in this band as it is also allocated to the radiolocation service on a secondary basis (not protected).

\section{Ground-Based Radar Systems}

DoD has two mobile ground based radar systems. The first is Ground Based Radar One (GB-1) which is specifically designed to locate the firing positions of both rocket and mortar launchers. The Army operates GB-1 radar at many locations within the U.S. However, the sites requiring exclusion zones provided in Table (3) was limited to the locations where the radar requires use of its full tuning range. The radar does not require use of the upper portion of its tuning range at the many other locations. Ground Based Radar Three (GB-3) is a multi-function system that provides surveillance, air traffic control and fire quality data [8]. The Ground-Based Radar Two (GB-2) are interference limited systems (as opposed to noise limited systems) and are associated with Airborne Radars.

Based on the NTIA analysis [8], it was concluded that there is a need for an exclusion zone to protect the ground-based radars. The exclusion zone creates separation distances on the order of several hundred kilometers. It should be noted that a number of "GB-1" and "GB-3" sites required limited exclusion zones protection. To accommodate this much-reduced number of exclusion zones, the radio frequency filter of the base stations would need to provide 30 to 40 $\mathrm{dB}$ of attenuation at $3500 \mathrm{MHz}$ (approximately $50 \mathrm{MHz}$ below the band of interest, 3550-3650 $\mathrm{MHz}$ ) to mitigate the potential of high-power interference effects. A plot of the exclusion zones is shown in Figure (8). The radius of the exclusion zones around the ground-based radar systems are given in Table (4).

\begin{tabular}{|l|l|}
\hline \multicolumn{1}{|c|}{ GB-1 Installation Name } & \multicolumn{1}{c|}{ GB-3 Installation Name } \\
\hline Fort Stewart, Georgia & MCB Camp Pendleton, California \\
\hline Fort Carson, Colorado & MCAS Miramar, California \\
\hline Fort Hood, Texas & MAGTFTC 29 Palms, California \\
\hline Fort Riley, Kansas & MCMWTC Bridgeport, California \\
\hline Fort Polk, Louisiana & MCAS Yuma, Arizona \\
\hline Fort Knox, Kentucky & MCB Camp Lejeune, North \\
\hline Fort Drum, New York & MCB Quantico, Virginia \\
\hline Fort Bragg, North Carolina & MCAS Cherry Point, North \\
\hline Fort Wainwright, Alaska & Bogue Field, North Carolina \\
\hline Fort Lewis, Washington & MCAS Beaufort, South Carolina \\
\hline White Sands Missile Range & Virginia Beach, Virginia \\
\hline Yuma Proving Ground & Fort Worth, Texas \\
\hline Fort Irwin, California & Cheyenne, Wyoming \\
\hline & Ft Sill, Oklahoma \\
\hline & Aurora, Colorado \\
\hline & Pensacola, Florida \\
\hline & Ft Bliss, Texas \\
\hline
\end{tabular}

Table (3): Ground-Based Radar - 1 and 3 Installation Locations 


\begin{tabular}{|c|c|c|c|c|c|c|}
\hline \multirow{2}{*}{$\begin{array}{c}\text { Radar to Wireless } \\
\text { Syste } \\
\mathbf{m} \\
\text { Interaction }\end{array}$} & \multicolumn{2}{|c|}{ Ground-Based Radar-1 } & Ground-Based Radar-2 & \multicolumn{2}{|c|}{ Ground-Based Radar - 3 } \\
\cline { 2 - 7 } & $\begin{array}{c}\text { Frequency } \\
\text { Offset } \\
\text { (MHz) }\end{array}$ & $\begin{array}{c}\text { Radius of } \\
\text { Exclusion } \\
\text { Zone } \\
(\mathbf{k m})\end{array}$ & $\begin{array}{c}\text { Frequency } \\
\text { Offset } \\
\text { (MHz) }\end{array}$ & $\begin{array}{c}\text { Radius of } \\
\text { Exclusion } \\
\text { Zone } \\
\text { (km) }\end{array}$ & $\begin{array}{c}\text { Frequency } \\
\text { Offset } \\
\text { (MHz) }\end{array}$ & $\begin{array}{c}\text { Radius of } \\
\text { Exclusion } \\
\text { Zone } \\
\text { (km) }\end{array}$ \\
\hline $\begin{array}{c}\text { Radar to Base } \\
\text { (Single Entry) }\end{array}$ & 50 & 40 & 40 & $<1$ & 50 & 63 \\
\hline $\begin{array}{c}\text { Radar to Mobile } \\
\text { (Single Entry) }\end{array}$ & 50 & $<1$ & 40 & $<1$ & 50 & 3.5 \\
\hline $\begin{array}{c}\text { Base and Mobile to } \\
\text { Radar (Aggregate) }\end{array}$ & 50 & 24 & 40 & $<1$ & 50 & 32 \\
\hline
\end{tabular}

Table (4): Summary of Exclusion Zones based on NTIA analysis, Ground-Based Radar Systems working at the full band (3500-3650 $\mathrm{MHz})$

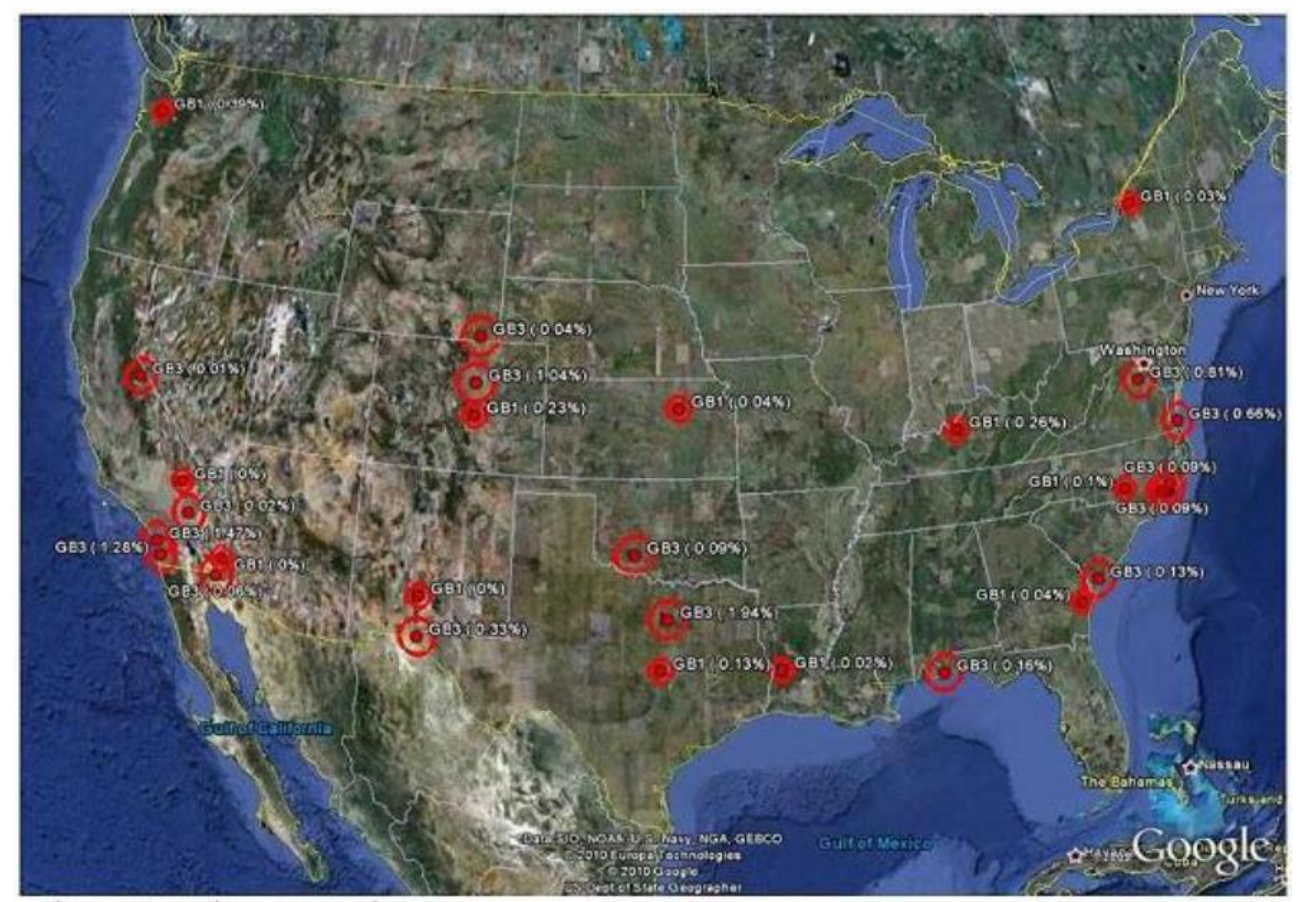

Figure (8): Plot of Exclusion Zones, Ground-Based Radar Systems.

\section{Airborne Radar Systems}

The NTIA concluded that, a frequency offset of $50 \mathrm{MHz}$ was needed in order to minimize the required separation distances. As shown in the analysis, co-frequency operation with the airborne radar systems would require large exclusion zones (in excess of $300 \mathrm{~km}$ ). Furthermore, establishing exclusions is generally not a practical approach to sharing with airborne systems. Therefore, NTIA concluded that a frequency offset of approximately $40 \mathrm{MHz}$ was needed to eliminate the need for exclusion zones for airborne radar systems ${ }^{14}$; see Table (5).

\footnotetext{
14 This is one of the rationales for limiting the sharing band to $3550-3650 \mathrm{MHz}$ instead of the full $3500-3650 \mathrm{MHz}$.
} 


\begin{tabular}{|c|c|c|c|c|}
\hline \multirow{2}{*}{$\begin{array}{c}\text { Radar to Wireless } \\
\text { System } \\
\text { Interaction }\end{array}$} & $\begin{array}{c}\text { Frequency } \\
\text { Offset } \\
\text { (MHz) }\end{array}$ & $\begin{array}{c}\text { Airborne Radar - 1 } \\
\text { Radius of } \\
\text { Exclusion } \\
\text { Zone (km) }\end{array}$ & $\begin{array}{c}\text { Frequency } \\
\text { Offset } \\
\text { (MHz) }\end{array}$ & $\begin{array}{c}\text { Airborne Radius of } \\
\text { Exclusion } \\
\text { Zone (km) }\end{array}$ \\
\hline $\begin{array}{c}\text { Radar to Base } \\
\text { (Single Entry) }\end{array}$ & 40 & $<1$ & 40 & $<1$ \\
\hline $\begin{array}{c}\text { Radar to Mobile } \\
\text { (Single Entry) }\end{array}$ & 40 & $<1$ & 40 & $<1$ \\
\hline $\begin{array}{c}\text { Base and Mobile to } \\
\text { Radar (Aggregate) }\end{array}$ & 40 & $<1$ & 40 & $<1$ \\
\hline
\end{tabular}

Table (5): Summary of Exclusion Zones based on NTIA analysis, Airborne Radar Systems

\section{Shipborne Radar Systems}

In shipborne radar case, the exclusion zone is defined by a distance from the coast line considering interference to and from the shipborne radar. In developing the exclusion zone distance (i.e. NTIA analysis), it was assumed that the shipborne radar was operating $10 \mathrm{~km}$ from the coastline. Figure (9) shows an example of expected exclusion zone for one of the shipborne radars.

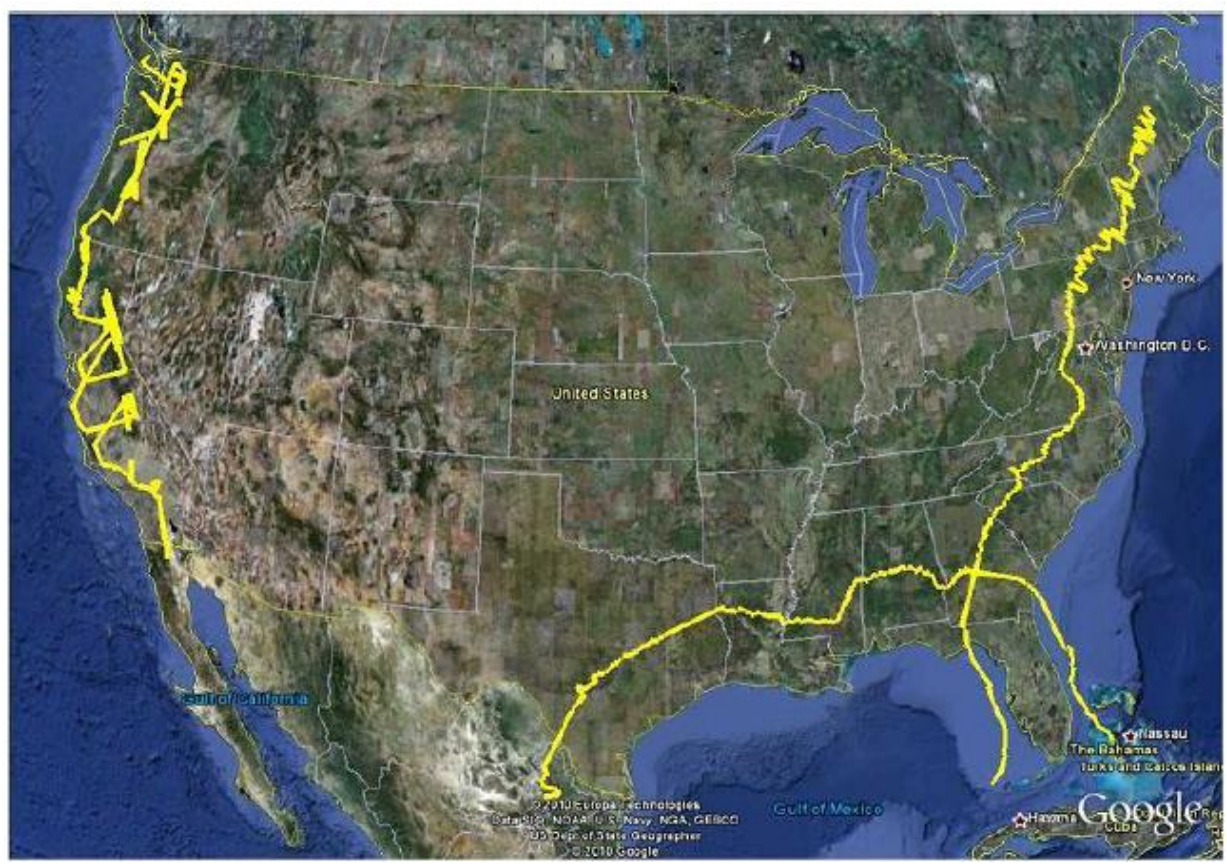

Figure (9): Exclusion Zone Distances for one type of Shipborne Radar Systems

\section{B. Why 3.5GHz?}

Based on the NTIA Fast Track Evaluation report [8], the $3500-3650 \mathrm{MHz}$ frequency range is divided into the $3500-3600$ and $3600-3650 \mathrm{MHz}$ bands in the U.S. National Table of Frequency Allocations. These two frequency bands include allocations to Federal radiolocation and radionavigation services. Therefore, since the bands represent similar uses throughout 3500- 
$3650 \mathrm{MHz}$ band, the $3500-3600$ and $3600-3650 \mathrm{MHz}$ bands have been addressed as a single frequency band in the NTIA analysis.

The reasons to select 3550-3650 MHz band by NTIA are: (1) WiMAX equipment has already been developed and deployed in this band within US (2) federal operations in the band are geographically limited; and (3) the band has already been allocated for fixed services in other parts of the world [8]. Based on [18], the spectrum sharing (geographically) in this band relies on exclusion zones along the U.S. coastline to protect base stations from high power U.S. Navy radar systems. Furthermore, exclusion zones will be required around a limited number of fixed land sites and some training and test sites to protect other military operations [8].

\section{Multi-Tiered Shared Access Model}

The FCC issued a Notice of Proposed Rulemaking and Order (NPRO) on December 12, 2012, in which they propose to create a new Citizens Broadband Service in the 3550-3650 MHz band [18]. The FCC proposed the idea of multi-tiered shared access model which reflects the PCAST report [6] recommendations. The FCC proposed that the $3.5 \mathrm{GHz}$ band be managed by a Spectrum Access System (SAS) incorporating a dynamic database. The SAS would ensure that multi-tiered users operate in a way that does not cause harmful interference to incumbent users and could also help manage interference protection among other users. The three tiers of service would be:

\section{Incumbent Access (IA)}

The IA tier would consist solely of authorized federal users at $3.5 \mathrm{GHz}$ band. These Incumbent access users would be protected from harmful interference from tier- 2 and tier-3 users through appropriate regulatory and technical means.

\section{Priority Access (PA)}

This Tier-2 access is relatively new to spectrum sharing. PA allows authorized users (mainly federal and utility agencies) to operate with minimal quality-of-service and with interference protection in portions of the $3.5 \mathrm{GHz}$ band wherever they exist. PA users would be eligible to use authorized devices on an interference protected basis within their facilities as controlled by the SAS.

The PA tier would be available only in areas where spectrum sharing does not cause any interference to the IA users; in addition, they do not expect to receive interference from IA users, see Figure (10). Those qualified PA users can expect protection from harmful interference from other operations from the same or lower tier of users within their facilities. The network used at this tier need not be small cell, though the FCC has not recommended any strategy in this regard.

\section{General Authorized Access (GAA)}

This is Tier-3 and it is equivalent to what is commonly called "secondary users". The GAA tier would be assigned for use by the general public using small cell technologies on an opportunistic, non-interfering basis. The GAA tier could include a wide range of residential 
or business including wireless telephone and Internet service providers. The FCC proposed to authorize GAA use in zones where small cell use would not interfere with IA or PA users.

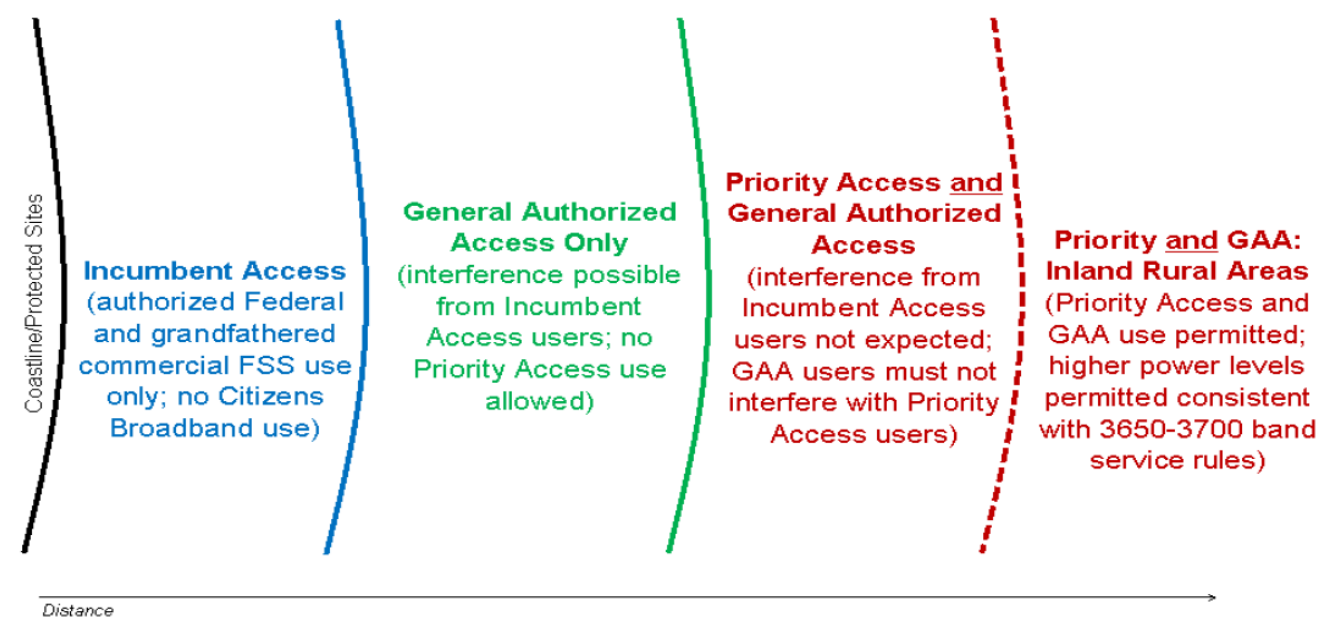

Figure (10): Conceptual illustration how the different tiers, and corresponding zones, might interrelate from a geographic perspective within the $3.5 \mathrm{GHz}$ Band [18].

\section{Small Cell Applications}

The PCAST report [6] and The FCC NPRO [18] recommended using small cell in $3.5 \mathrm{GHz}$ band as a way to allow spectrum sharing and increase spectral efficiency. Small cells are low-powered wireless base stations intended to cover small indoor or outdoor areas ranging in size from homes and offices to stadiums, shopping malls, and metropolitan outdoor spaces. They include femtocells, picocells, and microcells. Generally speaking, small cells are typically used to extend wireless coverage to areas with poor macro-cell coverage or where traffic is concentrated. It is expected that the first wave of these small cells at $3.5 \mathrm{GHz}$ band will be indoor as the first step on a gradual path toward outdoor small cell applications.

Neither the PCAST report nor the FCC document specifies the type of technology that will be used to provide small cell solutions. It will be left to the market to decide which is best to exploit this sharing opportunity. One of the major candidate is a LTE femtocells because many commercial LTE operators are seeking solutions to overcome the shortage in spectrum to keep up with the increase in mobile broadband traffic. Femtocells are an integral part of future LTE networks. It is part of the principle of heterogeneous networks (HetNets) where the mobile network is constructed with layers of small and large cells.

\section{E. Proposed Licensing Model}

There is some similarity in the proposed spectrum sharing approach with the television white spaces (TVWS). However, in this case we have three tiers of users, so the database must deal with two protected user classes (i.e. Incumbent and Priority Access users) which adds more 
complexity. The most important thing is that the licensing model should be light especially for the General Authorized Access users. As FCC mentioned in [18];

"We proposed to establish the Citizen's Broadband Service by rule under Section 307(e) of the Communications Act. We believe that a license-by-rule licensing framework would allow for rapid deployment of small cells by a wide range of users, including consumers, enterprises, and service providers, at low cost and with minimal barriers to entry. Much wireless broadband use occurs indoors or in other enclosed facilities. Typically, the owners or users of such facilities already have access to the siting permissions, backhaul facilities, electrical power, and other key non-spectrum inputs for the provision of service. Moreover, as explained above, our proposal for small cell operation at the relatively high frequency $3.5 \mathrm{GHz}$ Band would generally tend to contain service within such facilities, allowing for a very high degree of spectrum reuse. Therefore, authorizing these end users - or their agents or assignees - to have direct access to the $3.5 \mathrm{GHz}$ Band in the physical locations that they otherwise are able to access would seem to facilitate expeditious and low-cost provision of service. A license-by-rule framework is very compatible with and conducive toward these aims."

The IA users will be protected by an exclusion zone. This exclusion zones can take many forms that will be addressed late in this paper. The GAA uses the spectrum opportunistically with a light licensing regime (i.e. small cells). The new user type in this case study are the PA users. The FCC proposed that PA users will be authorized to operate within a substantial portion of contiguous spectrum (in this paper, we assume that $50 \mathrm{MHz}$ will be set for the Priority Access users), subject to the technical rules that are ultimately adopted in this proceeding. So, "PA eligible users" would be required to register their identity along with the location of their facilities in the SAS. The database would authorize PA use only by eligible users operating within eligible facilities within designated geographic areas. Also, the PA is different from traditional secondary access (e.g. unlicensed TVWS); see Figure (11).

IA: Incumbent Access PA: Priority Access GA: General Authorized Access

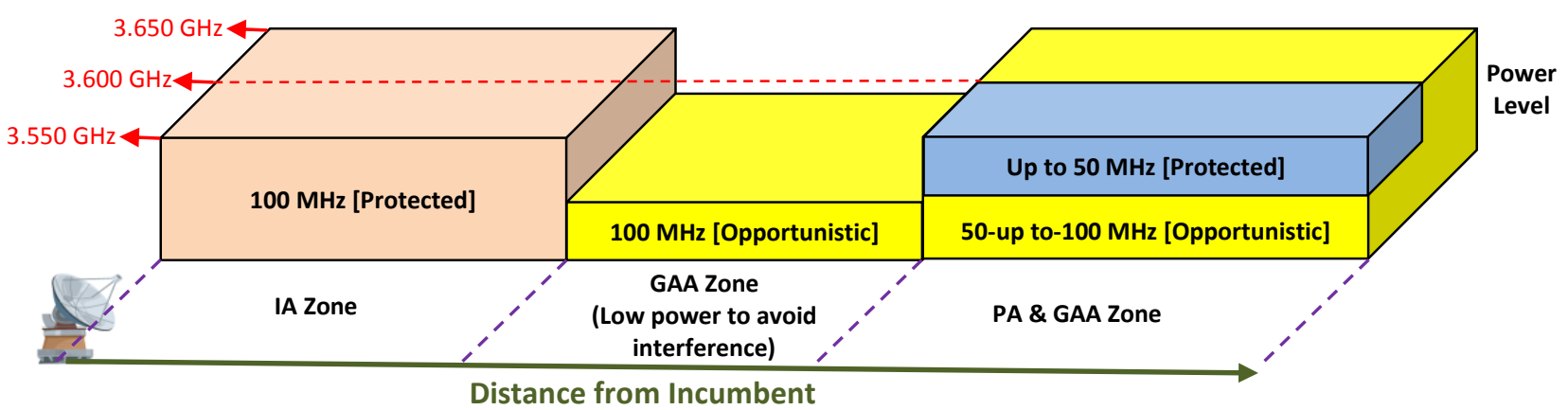

Figure (11): Illustration of how the licensing model will be. 
This licensing model may require adjustment with time and experience, so there should be some trials to explore different licensing scenarios. In addition, the size of the small cells can be different, and do not have to be the same all the time and everywhere. From Figure (11), they could be small in a "GAA zone" and relatively large in the "PA and GAA zone".

There should be a defined "interference threshold" from which it will be easy to distinguish the interference events. Interference can come from transmitter (regular interference event) or a poor receiver filter (bad design of incumbent receiver). It is expected that the radio vendors will favor a multilateral industry solution over a government run solution. This is generally similar to the tradeoff between ex ante (complicated device standardization) and ex post (simple standardization with powerful detection network to monitor the band) enforcement approaches.

\section{F. Exclusion Zones}

Figure (5) illustrates the how exclusion zones are related to each usage tier. The distance $\left(d_{1}\right)$ is based on the minimum distance that neither the PA nor the GAA users will cause harmful interference to the IA users. So, it will depend heavily on how the IA network will tolerate the interference. The distance $\left(d_{2}\right)$ is measured based on the minimum distance that the PA users will not receive any interference from the IA users, where the PA users expected protection from all type of harmful interference. The distance $\left(d_{3}\right)$ is only limited, by another (distant) GAA zone (i.e, another $d_{2}$ from other incumbent usages). Interference from IA users may be expected over the entire blue area. It should be noted that these boundaries are with respect to the IA users only. There are another domain or exclusion zones between the PA and GAA that are similar to MetSat case study.

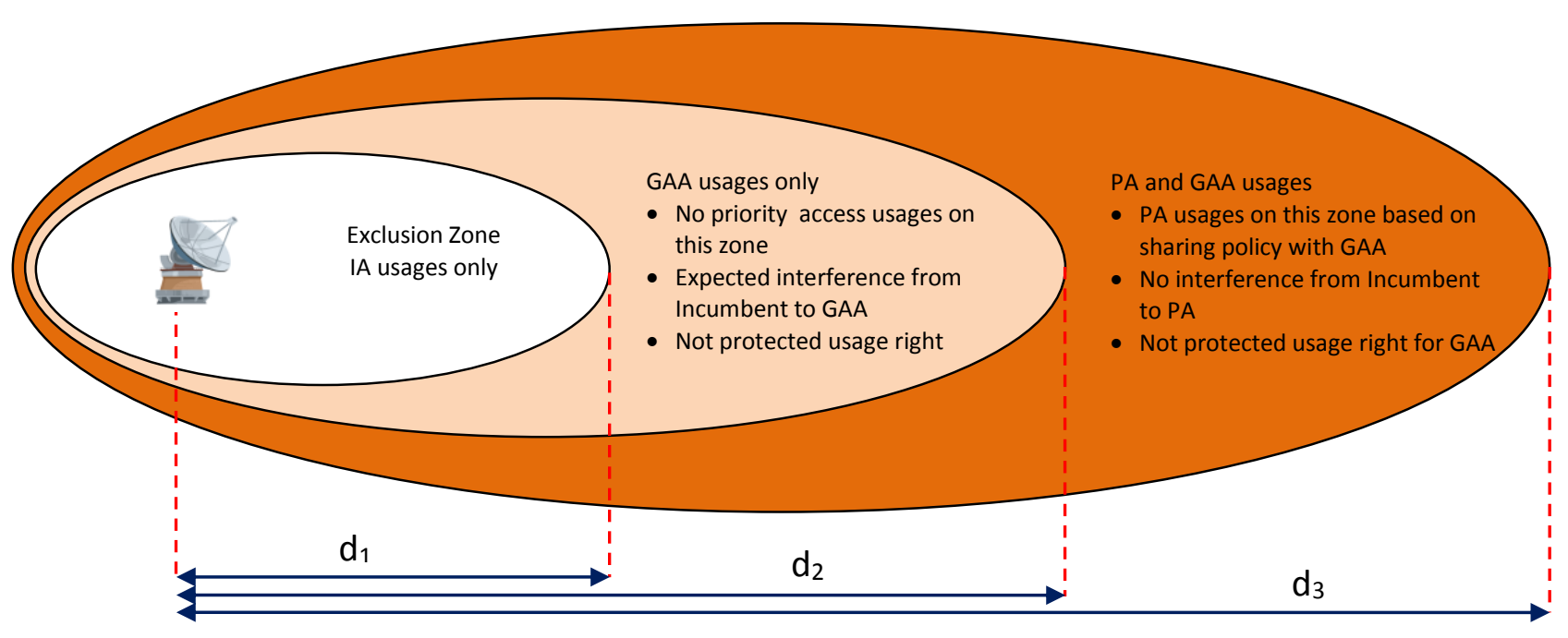

$\mathbf{d}_{\mathbf{1}}$ This distance is calculated based on the minimum distance that the PA and GAA users will may cause an interference to the Incumbent users (to prevent interference to the IA).

$\mathbf{d}_{\mathbf{2}}$ This distance base no possible interference from IA to PA users (not GAA).

$\mathbf{d}_{\mathbf{3}}$ This is an open distance from east-coast to the west-coast, unless there are another exclusion zone due to Incumbent ground-based system usages.

Figure (12): Illustration of exclusion zones. 


\section{G. The Role of Sensing}

Unlike the MetSat case, there is a need to sense the IA users (i.e. PUs) at the case sharing environment. The most challenging IA applications are the shipborne radars case. Since the IA user is a military user, tactical imperatives mean that neither their presence nor technical characteristics (signal shape, power level, etc.) will be available to GAA or PA users. A sensor network could be deployed to monitor the band for low level signal emissions that do not match the operating parameters of GAA or PA users. For shipborne radars, sensors could be deployed along the coasts, alerting users to the presence of a possible IA user. These users could then operate so as to avoid possible interference with the potential IA user. While this would leave GAA and PA users exposed to spoofing by malicious users, it would protect IA users. It would also make no requirements on IA users to reveal their location or their technical parameters.

Through an antenna pointing inland, the sensors could also detect the signal levels of GAA and PA users to ensure that signal levels are low enough to avoid interference. The sensor data fusion center (perhaps part of SAS) could proactively alert GAA users whose signal levels are too high. The sensor output may also be archived as evidence in a possible ex post adjudication claim.

The Continental US has approximately 12,383 miles of coastline ${ }^{15}$, so a sensor every 5 miles would mean that approximately 2400 sensors would need to be deployed for this application. The capital costs will vary significantly based on the required accuracy of its deliverables and the operating costs dependent heavily on backhaul. However, if local processing is performed so that only alerts are sent, backhaul may not require a high bit rate.

\section{H. Enforcement Scenarios}

\section{Exclusion Zones}

The exclusion zone for IA expected to cover many dense population areas and cities in the US. Large geographic exclusion zones would be imposed along the East, West, and Gulf Coasts to protect incumbent shipborne radar operations. Exclusion zones are also expected to protect ground-based radar systems.

Access to the $3.5 \mathrm{GHz}$ band will require new database systems that facilitate dynamic spectrum access. This database would be an operational mechanism by which each exclusion zone would be defined. Again, if exclusion zones are sized to avoid interference, then there may not be a strong basis for ex post action, except to determine the interfering station that may be located within the exclusion zone during the interference episode.

It may be impossible to take ex post action against a transmitter that was operating outside the exclusion zone even if caused co-channel interference to the IA user. This realization would cause IA users to argue for the largest exclusion zone possible. In the NTIA Fast Track Report recommended frequency and geographic separation to mitigate interference, assuming traditional macro-cell network deployments. NTIA recommended exclusion zones around ground-based and shipborne radar systems. With respect to shipborne radars, NTIA determined

\footnotetext{
${ }^{15}$ From http://www.worldatlas.com/webimage/countrys/namerica/usstates/uslandst.htm. Retrieved on 20 July
} 2013. 
that extremely large geographic exclusion zones are necessary, reaching a maximum of 557 kilometers from one type of shipborne radar into a base station located in the Gulf Coast region. Based upon NTIA's exclusion zone calculations for shipborne radar systems in $3.5 \mathrm{GHz}$ Band, we estimate that approximately 60 percent of the United States population fall within an exclusion zone. NTIA's analysis only considered WiMAX technology for shared use of the $3.5 \mathrm{GHz}$ Band. The small cell and access management technologies proposed in FCC NPRO [18] alter some of the assumptions in NTIA's analysis. Ex post enforcement in this scenario could be used to detect violations of the exclusion zone by SUs. The costs of the objectives are quite different.

It is expected that "exclusion scenario" is less likely to be applied at $3.5 \mathrm{GHz}$ band, due to the following:

- The expected size of exclusion zone is very large. It should be minimized at the expense of adding more ex post enforcement techniques.

- $100 \mathrm{MHz}$ is a valuable amount of spectrum in a very attractive band to commercial operators. By using exclusion zone only (ex ante) the opportunity cost will be very high.

- $\quad$ Based on figure (12) above:

$O$ By varying the size of exclusion zone, we are referring to the distance $\left(d_{1}\right)$ since $\left(d_{2}\right)$ is based on the level of interference from IA to PA users. This means the opportunity cost mentioned above is the opportunity cost for the GAA users only (not the PA).

- In reference to NTIA report, if large exclusion zones are maintained around the ground-based radar system, it is likely that GAA users cannot exploit this sharing opportunity in the southern half of the USA.

\section{Protection Zones}

In this scenario, the PA and GAA users would be allowed to share the spectrum with the IA users as long as the aggregate received co-channel interference at the IA antenna is below a yet to be determined threshold. So, protection zones are smaller than exclusion zones. The existence of this zone also implies a dynamic database that defines its boundary. Thus, this approach would have to use a database similar to the exclusion zone scenario. Because transmission could be permitted in the protection zone, its opportunity cost would likely be substantially lower than that of the exclusion zone.

Enforcement could involve unilaterally disabling those GAA users who are interfering with the IA or it could involve an adjudication procedure for assessing penalties (as part of ex post enforcement). In the former scenario, IA users minimize their technical risks whereas the latter case sets the stage for a more bi-laterally adaptive approach to sharing. If an adjudication procedure exists, then the interference events must be documented and attention paid to issues such as provenance and chain-of-custody, which requires back-end information system expenses.

One of the things that makes the ex post more complex at $3.5 \mathrm{GHz}$ case is that the GAA users (i.e. SUs) are most likely decentralized or at least multiple centralized operators. That adds more cost to the adjudication procedures. Moreover, the protection of PA adds another layer of complexity. 


\section{Ex Post Only}

As it is explaind before, the enforcement in this scenario relies exclusively on ex post enforcement. The penalties for interference would be set so that the PA and GAA users would have an incentive to discover profit maximizing protected zones while simultaneously protecting the IA from co-channel interference. That is, if the cost of interference is sufficiently high, the PA and GAA would find it advantageous to modify their behavior in a way that balances the consequence of interference with the consequence of not transmitting in a region.

The SAS would manage the spectrum sharing at $3.5 \mathrm{GHz}$ band and would ensure that the PA and GAA users would not operate in a manner that would cause harmful interference to the IA. In addition to the need for a database, this scenario requires the establishment and operation of a sensor network as well as the adjudication-oriented information system.

The big concern about this approach is the cost and complexity as well as the technical risk to the IA's operations. Due to the large borders of IA operations; it is technically challenging and expensive to build an ex post enforcement system that meets the IA user needs while being "reasonable" and lawful for the GAA users. The positive side is that the exclusion/protected zone would be minimized.

\section{Summary}

In this band, the ground based radars and shipborne radars need some kind of protection; however, there is no need to protect the airborne radars. It is proposed that $3.5 \mathrm{GHz}$ band be managed by a Spectrum Access System (SAS) incorporating a dynamic database. The SAS would ensure that multi-tiered users operate in a way that does not cause harmful interference to incumbent users and could also help manage interference protection among other users. The three tiers of service would be (1) Incumbent Access (2) Priority Access (3) General Authorized Access.

In this case study, three enforcement scenarios are illustrated. (1) "Exclusion zones" would be imposed along the East, West, and Gulf Coasts to protect incumbent shipborne radar operations and ground-based radar systems. The expected size of exclusion zone is very large. It should be minimized at the expenses of adding more ex post enforcement methodologies. This scenarion is less likely to be the adopted enforcement mechanism due to the high opportunity cost and the $100 \mathrm{MHz}$ is a valuable amount of spectrum in a very attractive band to commercial operators. (2) "Protected zones" rely on the idea to share the spectrum with the incumbent as long as the aggregate received co-channel interference at is below certain threshold. This is most likely to be the adopted enforcement scenario. (3) The third scenario is a logical extension of the protection zone concept to not define a zone at all, but simply to define a threshold that cannot be exceeded.

There are three tiers of users, so, the database must deal with two protected user classes (i.e. Incumbent and Priority Access users) which adds more complexity. The licensing model may not be right and accurate the first time; there should be a need for trials to explore different licensing scenarios. There should be a defined "interference threshold" from which it will be easy to distinguish the interference events whether it is caused by a transmitter or a poor receiver filter. 
The first wave could be indoor application only. A spectrum sharing test-bed is very important in the band.

\section{Conclusions and Future Research}

Spectrum sharing agreements that do not explicitly define obligations and their enforcement are essentially non-binding [9] and thus provide no protection for incumbents. The emergent nature of DSA systems suggests that enforcement approaches should allow for learning from direct experience as well as the experiences of other DSA systems.

In this paper, we consider the tradeoffs of different enforcement approaches by examining the sharing opportunity between Federal and commercial users. The analysis in this paper is based on the recognition that some interference events are inevitable in spectrum sharing. Thus, the ex ante and ex post enforcement mechanisms serve to separate the interference events by consequence on the primary user's operation and to reduce the probability of interference events that have a consequence that is considered significant.

In general, an enforcement approach is considered to be more precise if it more specifically differentiates legitimate users and uses from illegitimate ones [19]. The cost of this depends on some attributes of the system itself. Exclusion zones with their databases are part of the ex ante enforcement mechanisms. In the absence of sensing, they are relatively imprecise mechanisms. There are large payoffs to reduce the size of the exclusion zone, perhaps doing so by making it dynamic, and to distinguish legitimate uses and users from illegitimate ones. On the other hand, ex post mechanisms involve the adjudication of actual interference events; they typically involve collecting information that can be used in agreed-upon adjudication procedures. In the absence of particular procedures, we can assume this information would include the detection of interference events attributable to the $\mathrm{SU}(\mathrm{s})$. These are more precise (in general) but may be more costly and certainly are not helpful in a particular interference episode, as they cannot technically remediate harm. Instead, they act by deterring future events.

The overall lessons from this case study is that enforcement approaches, costs and tradeoffs are quite situation-specific. Further, it is as yet not possible to determine a "best" approach to enforcement as the costs of adjudication are highly uncertain and dependent on the particulars of the sharing circumstances. Despite this, we believe that, through detailed analysis of many spectrum sharing situations (similar to the two cases presented here), an array of useful approaches to enforcement will emerge. This is consistent with the notion of learning and harvesting "best practices" that was discussed in [9].

In the same way, abstract analyses of this kind are a relatively poor substitute for actual operation. We have much to learn about how sensing can assist spectrum sharing in practice, especially when it comes to matters of the required sensor density and what information is sufficient for adjudication, and how easy (or difficult) it is to acquire this information.

There are a few topics for future research that emerge from this paper. Most directly, additional case studies should be performed, such as the ones presented here, which will help build a "catalog" of enforcement approaches. Such a collection may enable the development of recommended initial approaches for various spectrum sharing circumstances. 
Practically, however, this line of research cannot meaningfully move forward in the absence of a better understanding of the costs of adjudication. These costs, in turn, depend on methods and systems used to collect data, determine fault, assess penalties, and handle appeals. If this can be routinized so that costs are low, then an adaptive, flexible ex-post-oriented approach to enforcement may be possible.

\section{Acknowledgement}

This work was supported by the U.S. National Science Foundation under Grants 1216186 and 1149442.

\section{References}

[1] Federal Communications Commission, "MOBILE BROADBAND: THE BENEFITS OF ADDITIONAL SPECTRUM," Oct. 2010.

[2] Cisco, "Cisco Visual Networking Index: Global Mobile Data Traffic Forecast Update, 20112016," 2012.

[3] Federal Communication Commission, "Spectrum policy task force report," FCC, Washington, DC, Nov. 2002.

[4] The National Broadband Plan , "The National Broadband Plan (Chapter 5 - Spectrum)," www.broadband.gov.

[5] Executive office of the president council of economic advisers, "THE ECONOMIC BENEFITS OF NEW SPECTRUM FOR WIRELESS BROADBAND," Feb. 2012.

[6] PCAST, "REPORT TO THE PRESIDENT REALIZING THE FULL POTENTIAL OF GOVERNMENTHELD SPECTRUM TO SPUR ECONOMIC GROWTH," July 2012.

[7] The National Telecommunications and Information Administration, "Plan and Timetable to Make Available 500 Megahertz of Spectrum for Wireless Broadband," Oct. 2010.

[8] The National Telecommunications and Information Administration, "An Assessment of the Near-Term Viability of Accommodating Wireless Broadband Systems in the 1675-1710 $\mathrm{MHz}, 1755-1780 \mathrm{MHz}, 3500-3650 \mathrm{MHz}$, and 4200-4220 MHz, 4380-4400 MHz Bands," Oct. 2010.

[9] M. Weiss, W. Lehr, L. Cui and M. Altamimi, "Enforcement in Dynamic Spectrum Access Systems," in TPRC, 2012.

[10] Committee Commerce Spectrum Management Advisory, "CSMAC Working Group 1 (WG1) 1695-1710 MHz ; Meteorological-Satellite," 18 June 2013.

[11] M. B. Weiss, M. Altamimi and L. Cui, "Spatio-Temporal Spectrum Modelling: Taxonomy and economic evaluation of context acquisition," Telecommunications Policy, vol. 36, no. 4, pp. 335-348, 2012. 
[12] R. Saruthirathanaworakun, J. Peha and L. Correia, "Opportunistic Sharing Between Rotating Radar and Cellular," Selected Areas in Communications, IEEE Journal, vol. 30, pp. 1900-1910, 2012.

[13] M. B. Weiss, M. Altamimi and M. McHenry, "Enforcement and Spectrum Sharing: A Case Study of the 1695-1710 MHz Band," in CrawnCom , 2013.

[14] The National Telecommunications and Information Administration, "Third Interim Progress Report on the Ten-Year Plan and Timetable," November 2012.

[15] M. B. Weiss, S. Delaere and W. H. Lehr, "Sensing as a Service: An exploration into the practical implementation of DSA," in IEEE DySPAN, Singapore, 2010.

[16] Commerce Spectrum Management Advisory Committee, "Final Report of Working Group 1 - 1695-1710 MHz Meteorological-Satellite," National Telecommunications and Information Agency, Washington DC, 22 Jan 2013.

[17] C. Bazelon, "The Economic Basis of Spectrum Value: Pairing AWS-3 with the $1755 \mathrm{MHz}$ Band is More Valuable than Pairing it with Frequencies from the $1690 \mathrm{MHz}$ Band," The Brattle Group, Washington DC, 2011.

[18] Federal Communications Commission, "NOTICE OF PROPOSED RULEMAKING AND ORDER," (FCC 12-148), December 12, 2012.

[19] H. E. Smith, "Exclusion Versus Governance: Two Strategies for Delineating Property Rights," The Journal of Legal Studies, vol. 3, no. S2, pp. S453-S87, 2002.

[20] Commerce Spectrum Management Advisory Committee, "Meteorological-Satellite (16951710 MHz)," CSMAC WG-1, Jan 17, 2013.

[21] M. Mishra, J. Hwang, D. Filippini, R. Moazzami, L. Subramanian and T. Du, "Economic Analysis of Networking Technologies for Rural Developing Regions," Springer, 2005.

[22] M. B. Weiss and M. Altamaimi, "The Cost of Knowing: An economic evaluation of context acquisition in DSA systems," in TPRC, 2011. 
Appendix A: Summary of "Analysis Results" at the NTIA Fast Track report (Oct 2010) [8]

The NTIA did technical analysis summarized as follow:

- Radiosonde Transmitter

As shown in the analysis and the simulation, radiosonde transmitters operating in the 1676-1683 $\mathrm{MHz}$ band will not cause interference to base station receivers operating above $1695 \mathrm{MHz}$.

- Radiosonde Receive Stations

Based on the analysis results, if mobile/portable station transmitters are limited to operation above $1695 \mathrm{MHz}$ there will be no interference to radiosonde receive stations.

- Meteorological-Satellite Transmitters

No interference to base station receivers is predicted from GOES transmitters and POES transmitters operating in and adjacent to the $1695-1710 \mathrm{MHz}$ band.

- Meteorological-Satellite Receive Stations

NTIA chose to limit its technical analysis and the development of exclusion zones to the systems that operate in the $1695-1710 \mathrm{MHz}$ portion of the band after considering a few factors. First, a large number of transportable Federal and non-Federal meteorologicalsatellite earth station receivers operate at a frequency of $1692.7 \mathrm{MHz}$. Many of these receivers support emergency management. Because they do not require licenses, the users and their locations are unknown. Furthermore, some of these receivers operate on mobile platforms. Therefore, it is not possible to develop exclusion zones around these earth stations. 


\section{Appendix B: Summary of Exclusion Zones Around Meteorological-Satellite Receive}

Stations [8]

\begin{tabular}{|c|c|c|c|}
\hline Earth Station Location & Latitude & Longitude & $\begin{array}{l}\text { Exclusion Zone } \\
\text { Radius (km) }\end{array}$ \\
\hline Wallops Island, Virginia & $375645 \mathrm{~N}$ & $752745 \mathrm{~W}$ & 90 \\
\hline Fairbanks, Alaska & $644814 \mathrm{~N}$ & $1475234 \mathrm{~W}$ & 90 \\
\hline Suitland, Maryland & $384900 \mathrm{~N}$ & $765100 \mathrm{~W}$ & 121 \\
\hline Miami, Florida & $254700 \mathrm{~N}$ & $801900 \mathrm{~W}$ & 110 \\
\hline $\begin{array}{l}\text { Kaena Point/Hickam Air Force } \\
\text { Base/Pearl Harbor, Hawaii }\end{array}$ & $211907 N$ & $1575521 \mathrm{~W}$ & 110 \\
\hline Sioux Falls, South Dakota & $433409 \mathrm{~N}$ & $963733 \mathrm{~W}$ & 80 \\
\hline Cincinnati, Ohio & $390608 \mathrm{~N}$ & $843036 \mathrm{~W}$ & 97 \\
\hline Rock Island, Illinois & $413104 \mathrm{~N}$ & $903346 \mathrm{~W}$ & 78 \\
\hline St. Louis, Missouri & $383526 \mathrm{~N}$ & $901225 \mathrm{~W}$ & 76 \\
\hline Vicksburg, Mississippi & $322123 N$ & $905129 \mathrm{~W}$ & 72 \\
\hline Omaha, Nebraska & $411532 \mathrm{~N}$ & $955520 \mathrm{~W}$ & 76 \\
\hline Sacramento, California & $383459 \mathrm{~N}$ & $1212939 \mathrm{~W}$ & 72 \\
\hline Elmendorf Air Force Base, Alaska $^{b}$ & $613600 \mathrm{~N}$ & $150000 \mathrm{~W}$ & 110 \\
\hline Anderson Air Force Base, Guam & $133452 \mathrm{~N}$ & $1445528 \mathrm{E}$ & 110 \\
\hline Monterey, California & $363600 \mathrm{~N}$ & $1215400 \mathrm{~W}$ & 110 \\
\hline Stennis Space Center, Mississippi & $302359 \mathrm{~N}$ & $893559 \mathrm{~W}$ & 110 \\
\hline Twenty-Nine-Palms, California $^{a}$ & $341746 \mathrm{~N}$ & $1160944 \mathrm{~W}$ & 110 \\
\hline Yuma, Arizona $^{\mathrm{a}}$ & $323924 \mathrm{~N}$ & $1143622 \mathrm{~W}$ & 110 \\
\hline \multicolumn{4}{|c|}{$\begin{array}{l}\text { Note a: Earth station is transportable. } \\
\text { Note b: Latitude and Longitude coordinates are for the center point of the exclusion zone, not the } \\
\text { MetSat receive location. }\end{array}$} \\
\hline
\end{tabular}


Appendix C: Types of Analysis Performed for the 3500-3650 MHz Band 16

\begin{tabular}{|c|c|c|}
\hline Transmitter & Receiver & Type of Analysis \\
\hline \multicolumn{3}{|c|}{ Ground-Based Radar } \\
\hline Radar & Base Station & Adjacent Band Single Entry \\
\hline Radar & Mobile/Portable Station & Adjacent Band Single Entry \\
\hline Base and Mobile/Portable Stations & Radar & Adjacent Band Aggregate \\
\hline \multicolumn{3}{|c|}{ Airborne Radar } \\
\hline Radar & Base Station & Adjacent Band Single Entry \\
\hline Radar & Mobile/Portable Station & Adjacent Band Single Entry \\
\hline Base and Mobile/Portable Stations & Radar & Adjacent Band Aggregate \\
\hline \multicolumn{3}{|c|}{ Shipborne Radar } \\
\hline Radar & Base Station & Co-Frequency Single Entry \\
\hline Radar & Mobile/Portable Station & Co-Frequency Single Entry \\
\hline Base and Mobile/Portable Stations & Radar & Co-Frequency Aggregate \\
\hline
\end{tabular}

\footnotetext{
${ }^{16}$ This table from NTIA Fast Track report "An Assessment of the Near-Term Viability of Accommodating Wireless Broadband Systems in the $1675-1710 \mathrm{MHz}, 1755-1780 \mathrm{MHz}, 3500-3650 \mathrm{MHz}$, and 4200-4220 MHz, 4380-4400 MHz Bands".
} 